A equipe editorial da Revista de Administração Pública (RAP) comunica a formal retratação para extração do artigo por não seguir as diretrizes editoriais do periódico.

Preusler, T. S., Costa, P. R., Crespi, T. B., \& Cirani, C. B. S. (2020). Capacidade relacional: um estudo da Empresa Brasileira de Pesquisa Agropecuária. Revista de Administração Pública, 54(5), 1307-1333. Recuperado em https://doi.org/10.1590/0034-761220190329

Preusler, T. S., Costa, P. R., Crespi, T. B., \& Cirani, C. B. S. (2020). Relational capability: a study of the Brazilian Agricultural Research Corporation. Revista de Administração Pública, 54(5), 1307-1333. Retrieved from https://doi.org/10.1590/0034-761220190329x

Profa. Dra. Alketa Peci

Editora-chefe 


\title{
Capacidade relacional: um estudo da Empresa Brasileira de Pesquisa Agropecuária
}

Taísa Scariot Preusler 1

Priscila Rezende da Costa ${ }^{1}$

Tatiane Baseggio Crespi 1

Claudia Brito Silva Cirani 1

1 Universidade Nove de Julho / Graduate Program of Business Administration, São Paulo / SP - Brasil

\begin{abstract}
A EMBRAPA desempenha papel importante em P\&D na geração de inovações. A maioria das inovações é gerada por meio de alianças de P\&D com parceiros externos, estimulando a capacidade relacional (CR), ou seja, um construto de gerenciamento estratégico de alianças com proposições de procedimentos que ainda não foram empiricamente verificados. Nesse contexto, investigamos como os processos de capacidade relacional contribuem para gerar inovações. Para tanto, realizamos pesquisa qualitativa utilizando um estudo de caso, baseado em entrevistas, análise de documentos e observação. Três alianças estratégicas de P\&D envolvendo a EMBRAPA e parceiros externos foram analisados. A principal contribuição para o avanço do conhecimento é um framework multidimensional para gerar inovações a partir de alianças estratégicas de $\mathrm{P} \& \mathrm{D}$, com base na evidência empírica dos processos da CR da EMBRAPA e de seus parceiros externos. Este novo framework lança luz sobre como uma empresa pública de pesquisa absorve conhecimento e descobre os processos de institucionalização e repercussão da CR.

Palavras-chave: inovação agrícola; alianças de P\&D; capacidade relacional; EMBRAPA.
\end{abstract}

\section{Capacidad relacional: un estudio de la Empresa Brasileña de Investigación Agrícola}

La EMBRAPA desempeña un papel importante en Investigación y Desarrollo (I+D) para generar innovaciones. La mayoría de las innovaciones se genera a través de alianzas de I+D con socios externos, estimulando la capacidad relacional (CR), es decir, un constructo de gestión estratégica de alianzas con propuestas de procedimientos que aún no se han verificado empíricamente. En este contexto, investigamos cómo los procesos de CR contribuyen a generar innovaciones. Para ello, realizamos una investigación cualitativa utilizando un estudio de caso basado en entrevistas, análisis de documentos y observación. Tres alianzas estratégicas de $\mathrm{I}+\mathrm{D}$ en las que participaron EMBRAPA y socios externos constituyeron el corpus de análisis. La principal contribución al avance del conocimiento es un framework multidimensional para generar innovaciones a partir de alianzas estratégicas de I $+\mathrm{D}$, con base en la evidencia empírica de los procesos de CR de EMBRAPA y sus socios externos. Este nuevo framework arroja luz sobre cómo una empresa pública de investigación absorbe el conocimiento y descubre los procesos de institucionalización y repercusión de la CR.

Palavras clave: innovación agrícola; alianzas de I+D; capacidad relacional; EMBRAPA.

\section{Relational capability: a study of the Brazilian Agricultural Research Corporation}

The Brazilian Agricultural Research Corporation (EMBRAPA) plays an important role in Research and Development (R\&D) for generating innovations. Most innovations are generated through R\&D alliances with external partners, stimulating relational capability (RC), that is, a construct of strategic management of alliances with propositions for procedures that have not yet been empirically verified. In this context, we investigated how relational capability processes contribute to generating innovations. We conducted qualitative research using a case study based on interviews, document analysis, and observation. Three strategic R\&D alliances involving EMBRAPA and external partners constituted the analysis corpus. The main contribution to knowledge advancement is a multidimensional fraProgmework for generating innovations from strategic R\&D alliances, based on the empirical evidence of processes of EMBRAPA relational capability and its external partners. This new framework sheds light on how a public research enterprise absorbs knowledge and uncovers the processes of institutionalization and relational capability spillover.

Keywords: agricultural innovation; R\&D alliances; relational capability; EMBRAPA.

DOI: http://dx.doi.org/10.1590/0034-761220190329

Artigo recebido em 16 set. 2019 e aceito em 29 abr. 2020.

ISSN: $1982-3134$ @) (1)

[Versão traduzida] 


\section{INTRODUÇÃO}

As alianças estratégicas são consideradas uma alternativa estrutural de inovação, pois permitem complementar recursos, acessar novos mercados e reduzir custos de produção (De Almeida \& Costa, 2017; Dyer \& Singh, 1998). No entanto, o treinamento para essas alianças não é um processo simples e o índice de insucesso é muito alto. As chances de uma aliança satisfatória aumentam se as instituições envolvidas desenvolverem a capacidade de trocar continuamente informações e conhecimento com seus parceiros (Patterson \& Ambrosini, 2015), criar uma estrutura de governança para a gestão de alianças (Milagres, Rezende, \& Silva, 2017), e selecionar parceiros apropriados, gerenciando conflitos e estabelecendo confiança mútua (Shakeri \& Radfar, 2017). As chances de sucesso aumentam se os parceiros criarem mecanismos de proteção para ativos (Costa \& Porto, 2014; Sorrentino \& Garraffo, 2010) que beneficiam todas as partes envolvidas (Wang \& Rajagopalan, 2015).

Esses processos de gerenciamento de alianças estratégicas integram a construção de Capacidade Relacional (CR) (Schilke \& Goerzen, 2010), como os resultados relacionais (conhecidos como rendas relacionais ou benefícios relacionais de ganhos econômicos) e resultados científicos e tecnológicos que só são alcançados em uma relação interorganizacional (Zhang, Li, \& Li, 2017).

Neste estudo, a CR é investigada a partir da perspectiva da capacidade dinâmica, que uma instituição busca por meio de rotinas organizacionais (Helfat et al., 2009), ou seja, comportamentos aprendidos e repetidos ao longo do tempo (Winter, 2003) para criar, expandir ou transformar a base de recursos (Helfat et al., 2009). Sua instrumentação seguiu o modelo de Schilke e Goerzen (2010), composta por uma construção multidimensional, baseada em rotinas e processos corporativos divididos em cinco dimensões: coordenação interorganizacional, transformação de alianças, aprendizagem, proatividade em alianças e portfólio de alianças. Este último não foi considerado, uma vez que a unidade de análise no estudo são as alianças díades, não o portfólio.

Apesar da relevância da CR e de seus resultados promissores, os procedimentos desse construto ainda precisam ser verificados empiricamente:

(a) A capacidade relacional pode se apresentar de forma diferente em empresas de pesquisa públicas que formam alianças de $\mathrm{P} \& \mathrm{D}$ com parceiros externos, conectados (quando o parceiro de inovação é impulsionado predominantemente pela demanda do mercado) (Lhuillery \& Pfister, 2009) e não conectado ao mercado (quando o parceiro de inovação é predominantemente impulsionado pela pesquisa) (Appio, Martini, Petruzzelli, Neirotti, \& Van Looy, 2017);

(b) Em uma empresa pública de pesquisa, é possível sistematizar processos de gestão de alianças estratégicas (Crossan, Lane, \& White, 1999), proporcionando oportunidades de adaptação ou replicação desses processos em futuras alianças. Assim, a CR pode ser considerada "amadurecida", ou seja, institucionalizada (Lorenzoni \& Lipparini, 1999);

(c) Nas alianças estratégicas de $P \& D$ de uma empresa pública de pesquisa, podem ocorrer transbordamentos de processos relacionais entre os parceiros, levando a melhorias internas, ou mesmo a adoção de novas práticas de P\&D (Walsh, Lee, \& Nagaoka, 2016).

Em geral, a ocorrência de CR em uma organização permite gerar inovações, transbordamento de rotinas, processos inerentes à pesquisa e desenvolvimento entre os parceiros da aliança. Portanto, surge a seguinte questão: Como a CR contribui para a geração de inovações agrícolas desenvolvidas 
em alianças estratégicas de P\&D, estabelecidas entre a EMBRAPA e parceiros externos? Assim, este estudo tem como objetivo trazer contribuições teóricas e práticas na área de CR, a partir da análise de como essa capacidade contribui para a geração de inovações agrícolas, desenvolvidas nas alianças estratégicas de P\&D.

Essas proposições requerem evidências empíricas, dado o importante papel que a inovação desempenha no setor agrícola no Brasil e porque as alianças estratégicas de P\&D têm sido cada vez mais utilizadas para gerar inovações. Neste estudo, explora-se como os processos de CR contribuem para gerar inovações (Walsh et al., 2016).

Investigou-se da perspectiva da capacidade dinâmica (Niesten \& Jolink, 2015) como uma empresa usa rotinas organizacionais (Helfat et al., 2009), ou comportamentos aprendidos e repetidos ao longo do tempo (Winter, 2003) para criar, expandir ou transformar sua base de recursos (Helfat et al., 2009), permitindo-lhe lidar com ambientes em mudança (Donada, Nogatchewsky, \& Pezet, 2015). Adotou-se o modelo de Schilke e Goerzen (2010) para operacionalização da pesquisa, modelo atual utilizado internacionalmente (283 citações), com as seguintes categorias de análise: coordenação interorganizacional, transformação de alianças, aprendizagem, proatividade em alianças e portfólio de alianças. Este último não foi considerado, uma vez que a unidade de análise no estudo são as díades de aliança, não o portfólio.

Considerou-se também alguns antecedentes da CR, nomeadamente a experiência no estabelecimento de alianças e governar estruturas de alianças (Schilke \& Gorzen, 2010). A experiência com a formação de alianças estratégicas anteriores permite que as organizações desenvolvam a capacidade de escolher parceiros potenciais para complementar, gerenciar (De Almeida \& Costa, 2017; Heimeriks \& Duysters, 2007), e fazer ajustes em seus recursos, quando necessário (Heimeriks \& Duysters, 2007). Empresas com estrutura de alianças com foco na administração de alianças podem centralizar informações e facilitar a comunicação entre setores (Hoang \& Rothaermel, 2005), desenvolvendo os meios para gerenciar alianças com mais eficiência (Heimeriks \& Duysters, 2007). No que diz respeito à estrutura de alianças, destaca-se a formalização da governança, ou seja, os diferentes níveis de formalização de uma aliança relacionados aos mecanismos de proteção patrimonial (Costa \& Porto, 2014; Sorrentino \& Garraffo, 2010), considerando os parceiros e objetos de alianças.

Em relação à contribuição para o avanço do conhecimento, este estudo permitiu a proposição de um modelo interorganizacional para gerar inovações por meio de alianças estratégicas de P\&D com base nas evidências empíricas de processos de capacidade relacional da Empresa Brasileira de Pesquisa Agropecuária (EMBRAPA) e seus parceiros externos. Este novo modelo lança luz sobre como uma empresa pública de pesquisa absorve conhecimento e fornece evidências sem precedentes de institucionalização e transbordamento de processos de CR.

\section{REFERENCIAL TEÓRICO}

Diferentes termos, com o mesmo significado, são utilizados para definir o construto CR na literatura, além de críticas, como latência de conceito (o que torna difícil capturar ou medir objetivamente, por exemplo) e o risco de circularidade (capacidade como entrada, saída ou resultado). Alguns sinônimos encontrados na literatura são: capacidade de interagir (Johnsen \& Ford, 2006), capacidade de aliança (Heimeriks \& Duysters, 2007), capacidade de gestão de aliança (Niesten \& Jolink, 2015; Schilke \& Goerzen, 2010), e colaboração interorganizacional (Yan et al., 2010). 
A capacidade relacional pode ser desenvolvida de diferentes maneiras e analisada a partir de diferentes perspectivas, como capacidades dinâmicas (Teece, 2007), rede de governança (Dyer \& Singh, 1998), e gerenciamento de rede (Rodriguez-Diaz \& Espino-Rodriguez, 2006). Este investigou a perspectiva das capacidades dinâmicas, definidas como "tipo de capacidade dinâmica com a capacidade de criar, estender ou modificar a base de recursos da empresa, aumentada para incluir os recursos de seus parceiros de aliança" (Helfat et al., 2009, p. 66).

A literatura destaca que as instituições tendem a ter um melhor desempenho quando possuem departamentos especializados, treinamento, avaliação de procedimentos e ferramentas codificadas, tais como diretrizes e modelos de contrato que auxiliam na gestão de uma aliança (Milagres et al., 2017). Isso permite centralizar, em um único lugar, a experiência adquirida em diferentes alianças, áreas, e negócios, e desenvolver rotinas para criar os melhores mecanismos de captura. Isso permite compartilhar e disseminar o conhecimento adquirido por meio de alianças, repassando para outros setores da empresa, permitindo sua utilização em futuras alianças, promovendo o bom desempenho da aliança (Milagres et al., 2017) e empresas (Kohtamäki, Rabetino, \& Möller, 2018).

O desenvolvimento da estrutura de alianças permite a criação de uma estrutura de governança adequada. Neste estudo, relacionou-se a estrutura de governança ao nível de formalização, ou seja, o uso de ferramentas de governança, como contratos formais, instrumentos de controle e cláusulas de propriedade para evitar a perda de controle dos direitos de propriedade (Costa \& Porto, 2014; Sorrentino \& Garraffo, 2010) desenvolvendo assim maior capacidade de contratar e desenvolver contratos (Ariño, Reuer, Mayer, \& Jané, 2014). Quanto maiores os riscos de interdependência do parceiro e de transação de aliança, mais inclusivos e especificamente definidos e concebidos são os contratos para prevenir oportunismo futuro (Ding, Dekker, \& Groot, 2013). A estrutura de governança é, portanto, relevante para a CR; no entanto, pode variar de acordo com o objetivo da aliança (pesquisa ou desenvolvimento) e o perfil do parceiro (conectado e não conectado ao mercado) (Lin \& Darnall, 2015).

Mecanismos formais de governança aumentam a confiança e o nível de relacionamento entre parceiros e compartilhamento de conhecimento (Sorrentino \& Garraffo, 2010). Por outro lado, uma estrutura de governança rígida pode reduzir a produção de P\&D inovadora. Assim, neste estudo, espera-se que instrumentos de curto e médio prazo e cláusulas contratuais formais sejam adotados para desenvolver soluções imediatas para o mercado, envolvendo a aplicação de tecnologias protegidas e organizações conectadas ao mercado com maior expertise no desenvolvimento de produtos e processos (Lhuillery \& Pfister, 2009).

Por sua vez, em alianças estabelecidas com organizações não diretamente ligadas ao mercado e com expertise em pesquisa (universidades públicas, institutos de pesquisa públicos e organizações sociais), prevê-se a adoção de instrumentos de longo prazo e cláusulas contratuais menos formais, visto que o objetivo é o avanço e a difusão do conhecimento científico oriundo da pesquisa básica e/ou aplicada (Etzkowitz, 2017; Lhuillery \& Pfister, 2009). Portanto, podemos estabelecer as seguintes proposições secundárias: P1: A estrutura de governança tende a ser mais formal quando alianças estratégicas são estabelecidas entre instituições públicas de pesquisa e organizações conectadas ao mercado; P2: A estrutura de governança tende a ser menos formal quando alianças estratégicas são estabelecidas entre instituições públicas de pesquisa e organizações não conectadas ao mercado; P3: A estrutura de governança tende a ser mais formal quando o propósito da aliança está relacionado ao desenvolvimento de curto ou médio prazo; e P4: A estrutura de governança tende a ser menos formal quando o propósito da aliança está relacionado à pesquisa de longo prazo. 
Uma empresa com experiência em alianças com diversos atores gera invenções de maior significado técnico e mais fáceis de serem introduzidas no mercado (Walsh et al., 2016). Isso porque a colaboração multidisciplinar permite a complementação de recursos e conhecimentos, como no caso de institutos de pesquisa (conhecimento científico) e empresas (mercado/conhecimento industrial) (Du, Leten, \& Vanhaverbeke, 2014). A experiência em alianças permite que as empresas acessem uma fronteira do conhecimento científico, bem como alternativas a equipamentos científicos avançados e instalações para conduzir pesquisas de ponta (Etzkowitz, 2017). As alianças estratégicas também aumentam o número de novos produtos em desenvolvimento, crescimento e diversificação da empresa a longo prazo (Kauppila, 2015).

Portanto, a experiência com diferentes atores é benéfica devido à maior sensibilidade na prospecção de informações e conhecimentos de múltiplas fontes externas. Consequentemente, espera-se que vários parceiros possam ser uma vantagem em alianças de pesquisa de longo prazo, tanto para o avanço da ciência e da sociedade como um todo. P5: Experiência no estabelecimento de alianças estratégicas com diferentes parceiros cria um potencial para a CR quando o objetivo é a pesquisa de longo prazo.

Por outro lado, quando a formação de alianças se repete entre os mesmos parceiros, o conhecimento é adquirido em ambos os lados e de maneiras diferentes que podem ser capturados, compartilhados, armazenados e usados em futuras estruturas interorganizacionais com os mesmos parceiros (Niesten \& Jolink, 2015). Quanto maior a repetição dos parceiros na formação de alianças, mais refinada esta relação se torna, à medida que padrões e rotinas são estabelecidos, facilitando a troca de informações e conhecimentos entre os parceiros, que podem determinar mais facilmente as tarefas que cada um deve realizar (Zollo, Reuer, \& Singh, 2002).

A recorrência de parceiros leva a uma maior agilidade, pois possibilita um conhecimento aprofundado sobre a cultura, procedimentos de gestão, pontos fortes e fracos, formas de atuação, crenças das partes envolvidas e como cada parceiro atua, facilitando a gestão da aliança, fortalecimento da confiança entre parceiros e aumento da eficácia das alianças (Zollo et al., 2002). A recorrência de parceiros também permite a elaboração de contratos detalhados com custos mais baixos, uma vez que cada parceiro possui conhecimento prévio (Zollo et al., 2002). Portanto, a replicação de parceiros pode ser vantajosa em alianças no que diz respeito ao desenvolvimento de soluções imediatas para o mercado. P6: A experiência na formação de alianças estratégicas com os mesmos parceiros potencializa a CR quando o objetivo é o desenvolvimento de curto e médio prazo.

Schilke e Goerzan (2010) definiram a CR como dimensionada da coordenação interorganizacional, aprendizagem interorganizacional, proatividade de aliança e transformação de aliança. A coordenação interorganizacional é composta por um conjunto de mecanismos e rotinas específicas que são construídas de forma consensual entre os parceiros para a execução das tarefas e investimentos dos recursos da aliança (Gulati, Lawrence, \& Puranam, 2005). A coordenação desempenha um papel importante nas alianças, facilitando a interação para garantir que as alianças individuais sejam gerenciadas de forma eficiente, principalmente com parceiros de natureza distinta, com dissimilaridades quanto aos seus objetivos e expectativas, mitigando e resolvendo conflitos interpretativos (Estrada, Faems, Cruz, \& Santana, 2016).

A aprendizagem organizacional está relacionada a rotinas e mecanismos para facilitar a articulação, codificação, compartilhamento e internalização de experiência de parceiros de aliança e transferência de conhecimento dentro dos limites da empresa (Shakeri \& Radfar, 2017). A aprendizagem organizacional também é conhecida como capacidade de absorção. É a capacidade dinâmica com que a empresa consegue criar novos recursos internos buscando, adquirindo, assimilando, transformando e explorando o conhecimento externo em um processo de inovação (Patterson \& Ambrosini, 2015). 
$\mathrm{Na}$ rotina de detecção, a proatividade permite que as organizações identifiquem potenciais oportunidades e parceiros para a aquisição de recursos externos (Schilke \& Goerzen, 2010). Empresas proativas podem responder e agir de forma preventiva a novas oportunidades (Schilke \& Goerzen, 2010). A transformação da aliança está relacionada à flexibilidade dos parceiros para reagir às condições a serem alteradas em toda a aliança (Reuer \& Zollo, 2000). Mudanças em contratos, mecanismos de governança e pessoal são recorrentes em aproximadamente $40 \%$ das alianças estratégicas. Portanto, se as instituições parceiras desenvolverem rotinas que modificam as alianças, estas são capazes de alavancar recursos complementares e aprender umas com as outras ao lidar com os desafios colocados por conflitos, gastos inesperados e risco moral, após a formação da aliança.

Quando as empresas estabelecem estruturas organizacionais e pessoas especializadas, os processos de gestão estratégica das alianças de $P \& D$ podem ser institucionalizados (Crossan et al., 1999), já que se espera ter alcançado CR madura. P7: À medida que as empresas institucionalizam os processos de coordenação interorganizacional, sua proatividade nas alianças, seu aprendizado organizacional e transformação de alianças, seu CR torna-se mais maduro.

Institutos de pesquisa (não conectados ao mercado) são considerados importantes parceiros de $\mathrm{P} \& \mathrm{D}$, pois realizam pesquisas para desenvolver novos conhecimentos e tecnologias em áreas específicas, contribuindo para inovações (Du et al., 2014; Etzkowitz, 2017). Por outro lado, instituições ligadas ao mercado estão imbricadas com práticas para inovações de mercado (Lundvall, 1988). Desta forma, em alianças de $\mathrm{P} \& \mathrm{D}$, há um transbordamento de processo interorganizacional entre as empresas e seus parceiros. Em outras palavras, esses atores institucionalizam e posteriormente transferem processos inerentes às atividades de $\mathrm{P} \& \mathrm{D}$, resultando em aprimoramento ou novas práticas de absorção de conhecimento. P8: Em alianças estratégicas de $P \& D$, os processos inerentes à pesquisa são transferidos da empresa de pesquisa pública para os parceiros (conectado ou não conectado); e P9: Nas alianças estratégicas de $P \& D$, os processos inerentes ao desenvolvimento são encaminhados dos parceiros (ligados ou não ao mercado) para a empresa pública de pesquisa.

\section{METODOLOGIA}

Para atingir o objetivo geral desta pesquisa, o modelo utilizado foi desenvolvido por Schilke e Goerzen (2010), cuja análise é quantitativa, evidenciando a necessidade de avaliar como a experiência em aliança e a estrutura da aliança contribuem para o desenvolvimento da CR entre os parceiros. Para a compreensão desses fatores, utilizou-se de um estudo qualitativo, pois permite a aproximação do sujeito e do objeto: "Envolve com empatia os motivos, intenções, projetos dos atores, a partir dos quais as ações, estruturas e relações tornam-se significativas” (Minayo \& Sanches, 1993, p. 244). Além disso, neste tipo de pesquisa, a amostra é pequena, permitindo um estudo aprofundado sobre o tema (Collis \& Hussey, 2005).

Portanto, foi realizado um estudo qualitativo por meio da interação entre o pesquisador, participantes e locais estudados para esclarecer conceitos. O ambiente das alianças estudadas foi utilizado como fonte de dados e o pesquisador teve papel fundamental na coleta desses dados e na seleção, verificação e interpretação das informações (Creswell, 2017). Utilizamos uma abordagem exploratória por meio da interação entre o pesquisador, os participantes e os locais estudados para esclarecer conceitos (Marconi \& Lakatos, 2006). Utilizamos um estudo de caso, uma vez que não há domínio sobre as alianças em questão. Isso permitiu verificar, vincular e comparar as informações obtidas (conhecimento prático) com as proposições do estudo (conhecimento teórico) (Godoy, 1995). 
A unidade de análise selecionada foi a EMBRAPA, por atender aos seguintes critérios: a) reconhecimento como um dos principais atores da pesquisa agropecuária brasileira; b) experiência na formação de alianças para o desenvolvimento de inovações agrícolas; e c) evidências na CR, pois promove integração e interação entre os diversos atores do Sistema Nacional de Pesquisa Agropecuária, inclusive com fins lucrativos (empresas, cooperativas, institutos de pesquisa privados) e organizações sem fins lucrativos (universidades públicas, institutos de pesquisa públicos e organizações sociais).

Selecionamos três alianças para serem analisadas com base no seguinte: alianças estratégicas de $\mathrm{P} \& \mathrm{D}$ que geraram inovações relevantes do ponto de vista social, econômico ou ambiental; e alianças estratégicas concluídas nos últimos 15 anos. Esse período foi escolhido porque a EMBRAPA tem um histórico de desenvolvimento de cultivares de plantas, o que leva em média 12 anos. Isso permitiu que alianças de $\mathrm{P} \& \mathrm{D}$ em pesquisas de longo prazo fossem incluídas no estudo.

Foram consultados produtos, processos e serviços no site da EMBRAPA (https://www.embrapa.br/ produtos-processos-e-servicos) e soluções tecnológicas desenvolvidas pela empresa. Quando filtrado para o período de 2002 a 2017, o site apresentou 1.794 tecnologias. Este resultado inclui tecnologias geradas pela EMBRAPA e pela EMBRAPA e seus parceiros externos. Posteriormente, consultamos as cultivares registradas pela EMBRAPA no Registro Nacional de Cultivares (RNC) (http://www.agricultura. gov.br/guia-de-servicos/registro-nacional-de-cultivares-rnc). Em janeiro de 2017, a EMBRAPA possuía aproximadamente 1.580 cultivares cadastradas. Por fim, consultamos o site do Instituto Nacional da Propriedade Industrial para identificar patentes já registradas ou solicitadas pela EMBRAPA.

Considerando as alianças estratégicas formadas pela EMBRAPA com parceiros externos para o desenvolvimento de tecnologias, com base nos critérios acima mencionados, três alianças de P\&D foram selecionadas para o estudo: a) Embalagem anatômica para frutas, desenvolvida pela Unidade Agroindustrial de Alimentos da EMBRAPA e institutos públicos de pesquisa (IMA e INT), inovação com benefícios ambientais, econômicos e sociais, resultando em 39 patentes; b) Cultivares de cevada - BRS Quaranta, desenvolvido pela EMBRAPA Unidade Trigo, Fundação de Pesquisa (FAPA) e a empresa (AmBev), inovação que resultou em benefícios econômicos e sociais. Além disso, $90 \%$ das cultivares de cevada para melhoramento existentes no mercado foram desenvolvidas pela EMBRAPA; e c) INOVA-Bti - inseticida, desenvolvido pela Unidade de Recursos Genéticos e Biotecnologia da EMBRAPA, instituto privado de pesquisa (IMAmt) e uma cooperativa (Comdeagro), inovação de grande benefício social, pois reduz a proliferação do mosquito Aedes aegypti, inseto hospedeiro dos vírus dengue, chikungunya e zika.

Foram realizadas 10 entrevistas: três com os chefes de T\&T das unidades cujas inovações foram selecionadas; um com o chefe da Unidade de Recursos Genéticos e Biológicos (CENARGEN); e seis com pesquisadores que participaram diretamente das atividades de P\&D e da coordenação das alianças selecionadas, três da EMBRAPA e três de instituições parceiras que atuaram diretamente nas alianças para o desenvolvimento de tecnologias nas unidades. Exceto pela entrevista com o pesquisador da FAPA, que foi realizada via Skype, todos as outras foram conduzidas pessoalmente. Também foram entrevistados por telefone a Coordenadora de Apoio à Inovação e Propriedade Intelectual da EMBRAPA para identificar as características relacionadas à formação das alianças da EMBRAPA e ao processo de formalização. Também buscamos entender as questões de propriedade intelectual e a duração das alianças com diferentes objetivos. Nas entrevistas, utilizamos um roteiro semiestruturado, seguindo um modelo proposto por Schilke e Goezen (2010), e todas as entrevistas foram gravadas, totalizando seis horas e 48 minutos. 
Neste estudo, também foi utilizada a observação, pois permite ao pesquisador identificar e obter informações do ambiente e das expressões, comportamentos, fatos e sentidos dos indivíduos durante as entrevistas in loco. (Zamberlan et al., 2014). Essas informações foram registradas em um diário de campo.

Foram obtidos dados secundários no site da EMBRAPA e seus parceiros, consultando as cultivares registradas na RNC da EMBRAPA e recolhendo e confirmando informações sobre patentes por meio de consulta ao site do Instituto Nacional de Propriedade Industrial. Também analisamos documentos, como contratos, projetos e pastas, arquivos, relatórios, atas de reuniões, regulamentos, jornais e revistas. As diferentes fontes de dados (entrevistas semiestruturadas, documentos e observação não participante) permitiram analisar os temas sob diferentes perspectivas e compará-los para chegar a conclusões consistentes, um procedimento conhecido como triangulação (Zamberlan et al., 2014).

A técnica de análise de conteúdo para estudar as informações coletadas nas entrevistas foi utilizada, permitindo a organização quantitativa e classificação da informação em categorias sistematizadas, o que, por sua vez, ajudou a reduzir a quantidade de dados coletados, garantindo informações precisas (Marconi et al., 2006).

A síntese da matriz de amarração pode ser vista no Quadro 1.

\section{QUADRO 1 MATRIZ METODOLÓGICA DE AMARRAÇÃO}

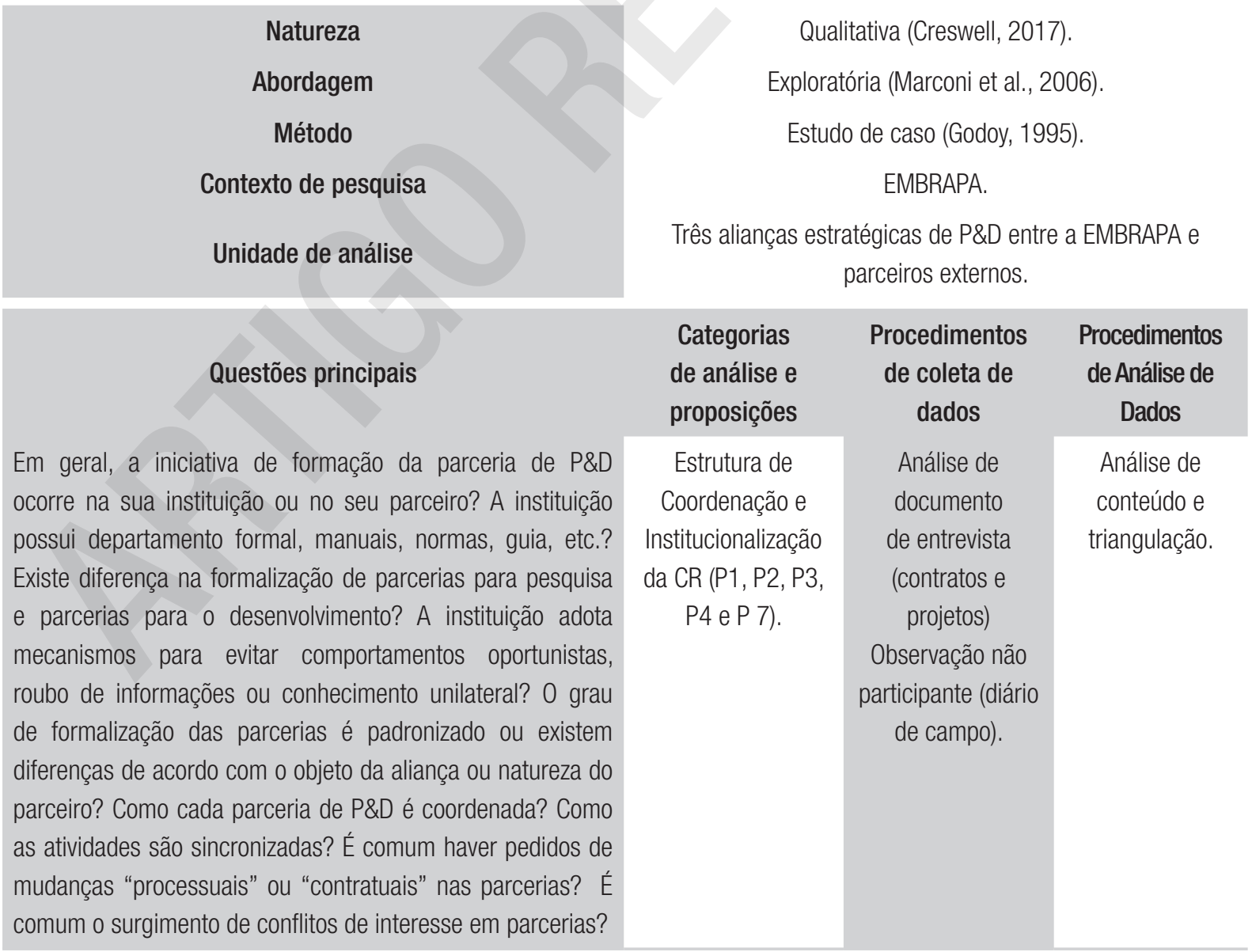




\begin{tabular}{|c|c|c|c|}
\hline Questões principais & $\begin{array}{l}\text { Categorias } \\
\text { de análise e } \\
\text { proposições }\end{array}$ & $\begin{array}{l}\text { Procedimentos } \\
\text { de coleta de } \\
\text { dados }\end{array}$ & $\begin{array}{l}\text { Procedimentos } \\
\text { de Análise de } \\
\text { Dados }\end{array}$ \\
\hline $\begin{array}{l}\text { A experiência no estabelecimento de parcerias contribui para } \\
\text { a gestão estratégica de parcerias para a inovação? É comum } \\
\text { ter parcerias repetidas com o mesmo parceiro? }\end{array}$ & $\begin{array}{l}\text { Experiência em } \\
\text { estabelecer alianças } \\
\text { (P5 e P6). }\end{array}$ & $\begin{array}{c}\text { Análise de } \\
\text { documento } \\
\text { de entrevista } \\
\text { (contratos e } \\
\text { projetos) } \\
\text { Observação não } \\
\text { participante (diário } \\
\text { de campo). }\end{array}$ & $\begin{array}{l}\text { Análise de } \\
\text { conteúdo e } \\
\text { triangulação. }\end{array}$ \\
\hline $\begin{array}{l}\text { Qual a percepção da Instituiçãa quanto à formação de parcerias de } \\
\text { P\&D? Quais conhecimentos, recursos ou ativos foram buscados } \\
\text { para esta parceria? Sua instituição pode aprender com os parceiros? } \\
\text { Existem também rotinas e processos de transferência desse } \\
\text { conhecimento? Quais atividades cada parceiro desenvolveu? Qual } \\
\text { é a principal experiência do seu parceiro? Quais são os principais } \\
\text { impactos dessa inovação? }\end{array}$ & $\begin{array}{l}\text { Transborda-mento } \\
\text { de processos } \\
\text { inerentes à } \\
\text { pesquisa e } \\
\text { desenvolvimento } \\
\text { (P8 e P9). }\end{array}$ & $\begin{array}{c}\text { Análise de } \\
\text { documento } \\
\text { de entrevista } \\
\text { (contratos e } \\
\text { projetos) } \\
\text { Observação não } \\
\text { participante (diário } \\
\text { de campo). }\end{array}$ & $\begin{array}{l}\text { Análise de } \\
\text { conteúdo e } \\
\text { triangulação. }\end{array}$ \\
\hline
\end{tabular}

Fonte: Dados de pesquisa elaborado pelos autores.

\section{RESULTADOS}

Considerando as características das alianças em questão, bem como a descrição dos parceiros envolvidos e das inovações geradas, a seguir, apresenta-se um resumo dos casos (Quadro 2).

\section{QUADRO 2 SÍNTESE INTRA-CASO DA ALIANÇA ESTRATÉGICA DE P\&D PESQUISADAS}

\begin{tabular}{|c|c|c|c|}
\hline \multirow[b]{2}{*}{ Características } & \multicolumn{3}{|c|}{ Descrição sintetizada } \\
\hline & $\begin{array}{l}\text { Aliança (1) } \\
\text { Embalagem anatômica para } \\
\text { frutas }\end{array}$ & $\begin{array}{c}\text { Aliança (2) } \\
\text { Cultivo de cevada - BRS } \\
\text { Quaranta }\end{array}$ & $\begin{array}{c}\text { Aliança (3) } \\
\text { INOVA-Bti - inseticida biológico }\end{array}$ \\
\hline Tipo de inovação & Processo agroindustrial. & Produto (eco inovação). & Produto. \\
\hline Tópico relacionado & $\begin{array}{c}\text { Agronegócio, segurança } \\
\text { alimentar, nutrição e saúde. }\end{array}$ & $\begin{array}{l}\text { Agricultura familiar, } \\
\text { agroindústria, melhoramento } \\
\text { genético e produção vegetal. }\end{array}$ & $\begin{array}{l}\text { Produtos biológicos e formulações } \\
\text { semelhantes. }\end{array}$ \\
\hline $\begin{array}{l}\text { Ano de } \\
\text { lançamento }\end{array}$ & 2011 & 2002 & 2016 \\
\hline Ano de conclusão & 2015 & 2015 & 2016 \\
\hline $\begin{array}{l}\text { Aplicações } \\
\text { principais }\end{array}$ & $\begin{array}{c}\text { Transporte e armazenamento } \\
\text { de frutas. }\end{array}$ & Cultura de inverno. & $\begin{array}{l}\text { Reservatórios de água potável, locais } \\
\text { propícios à proliferação ou ligados a } \\
\text { outros meios de controle do mosquito. }\end{array}$ \\
\hline
\end{tabular}




\begin{tabular}{|c|c|c|c|}
\hline \multirow[b]{2}{*}{ Características } & \multicolumn{3}{|c|}{ Descrição sintetizada } \\
\hline & $\begin{array}{c}\text { Aliança (1) } \\
\text { Embalagem anatômica para } \\
\text { frutas }\end{array}$ & $\begin{array}{c}\text { Aliança (2) } \\
\text { Cultivo de cevada - BRS } \\
\text { Quaranta }\end{array}$ & $\begin{array}{c}\text { Aliança (3) } \\
\text { INOVA-Bti - inseticida biológico }\end{array}$ \\
\hline Principais impactos & $\begin{array}{l}\text { Redução de perdas e } \\
\text { desperdício de frutas; maior } \\
\text { eficiência no trabalho; } \\
\text { decomposição mais rápida na } \\
\text { natureza. }\end{array}$ & $\begin{array}{l}\text { Aumento de produtividade; } \\
\text { dispensação parcial ou total de } \\
\text { aplicações de fungicidas. }\end{array}$ & $\begin{array}{l}\text { Controle de larvas do mosquito Aedes } \\
\text { aegypti, inseto hospedeiro do vírus } \\
\text { da dengue, chikungunya e zika; não } \\
\text { agride o meio ambiente. }\end{array}$ \\
\hline $\begin{array}{l}\text { Depósitos de } \\
\text { patentes }\end{array}$ & 39 & 1 & Não aplicável (segredo industrial). \\
\hline Publicações & 4 artigos e 2 capítulos. & 1 pasta. & 1 pasta. \\
\hline Atividades d & $\begin{array}{l}\text { Pesquisa: levantamento dos } \\
\text { problemas encontrados pelos } \\
\text { produtores para o transporte } \\
\text { e armazenamento de frutas } \\
\text { e hortaliças; seleção da fibra } \\
\text { mais adequada para compósito. } \\
\text { Desenvolvimento: adicionar } \\
\text { fibra composta, modelagem e } \\
\text { design de embalagem. }\end{array}$ & $\begin{array}{c}\text { Desenvolvimento: } \\
\text { melhoramento genético } \\
\text { da cevada; Pesquisa: } \\
\text { experimentação para avaliar o } \\
\text { desempenho agronômico das } \\
\text { linhagens. }\end{array}$ & $\begin{array}{l}\text { Indicação de cepas; otimização do } \\
\text { processo de produção das cepas; } \\
\text { desenvolvimento de formulações } \\
\text { de alta qualidade e avaliação da } \\
\text { toxicidade dos produtos. }\end{array}$ \\
\hline Parceiros chave & $\begin{array}{c}\text { IMA (não conectado ao } \\
\text { mercado) e INT (não conectado } \\
\text { ao mercado). }\end{array}$ & $\begin{array}{c}\text { AmBev (conectada ao mercado) } \\
\text { e FAPA (não conectada ao } \\
\text { mercado). }\end{array}$ & $\begin{array}{l}\text { IMAmt (não conectado ao mercado) e } \\
\text { Comdeagro (conectado ao mercado). }\end{array}$ \\
\hline Começo da aliança & 2010 & 2002 & 2016 \\
\hline $\begin{array}{l}\text { Duração da } \\
\text { aliança * }\end{array}$ & 5 anos (médio prazo *). & 12 anos (longo prazo *). & 1 ano (curto prazo *). \\
\hline $\begin{array}{l}\text { Ferramenta de } \\
\text { formalização }\end{array}$ & Termo de acordo. & $\begin{array}{c}\text { Acordo de cooperação técnica } \\
\text { e financeira. }\end{array}$ & Acordo de Cooperação Técnica. \\
\hline Objetivo da aliança & $\begin{array}{l}\text { Desenvolvimento de } \\
\text { embalagens recuperáveis } \\
\text { para embalagens de frutas e } \\
\text { vegetais. }\end{array}$ & $\begin{array}{l}\text { Estabelecimento das } \\
\text { condições de cooperação } \\
\text { técnica e financeira entre a } \\
\text { EMBRAPA, AmBev e FAPA para } \\
\text { conquistarem novas cultivares } \\
\text { de cevada. }\end{array}$ & $\begin{array}{c}\text { Desenvolvimento de produtos à } \\
\text { base de Bacillus thuringiensis var. } \\
\text { israelenses e no Bacillus sphaericus, } \\
\text { para controle de Simulium spp, Culex } \\
\text { quinquefasciatua, Anopheles spp e } \\
\text { Aedes aegypti. }\end{array}$ \\
\hline $\begin{array}{l}\text { Composição do } \\
\text { recurso financeiro }\end{array}$ & $\begin{array}{l}\text { BNDES: 7,500,217.00 BRL; } \\
\text { IMA, INT e EMBRAPA: R\$ } \\
\text { 4.179.000,00 (contribuição). }\end{array}$ & $\begin{array}{c}\mathrm{R} \$ \text { 4.199.195,30, com } \\
\text { 1.568.972,30 referente à } \\
\text { participação da EMBRAPA; R\$ } \\
\text { 1.362.612,00, da AmBev; e } \\
\text { 1.267.611,00 BRL, e FAPA. }\end{array}$ & $\begin{array}{l}\text { Sem transferência de recursos } \\
\text { financeiros entre as instituições. } \\
\text { Valores contribuídos: EMBRAPA R\$ } \\
\text { 120000,00; IMAmt } R \$ 60.000,00 ; \\
\text { Comdeagro } \mathrm{R} \$ 60.000,00 \text {. }\end{array}$ \\
\hline
\end{tabular}




\begin{tabular}{|c|c|c|c|}
\hline \multirow[b]{2}{*}{ Características } & \multicolumn{3}{|c|}{ Descrição sintetizada } \\
\hline & $\begin{array}{c}\text { Aliança (1) } \\
\text { Embalagem anatômica para } \\
\text { frutas }\end{array}$ & $\begin{array}{c}\text { Aliança (2) } \\
\text { Cultivo de cevada - BRS } \\
\text { Quaranta }\end{array}$ & $\begin{array}{c}\text { Aliança (3) } \\
\text { INOVA-Bti - inseticida biológico }\end{array}$ \\
\hline $\begin{array}{l}0 \text { papel da } \\
\text { EMBRAPA }\end{array}$ & $\begin{array}{l}\text { Levantamentos das } \\
\text { necessidades de cada produto, } \\
\text { características de embalagem } \\
\text { adequadas. }\end{array}$ & $\begin{array}{l}\text { Atividades de cruzamento; } \\
\text { avanço de gerações e seleção } \\
\text { de progênies e desempenho de } \\
\text { avaliação e testes de valor da } \\
\text { safra e uso - vCU. }\end{array}$ & $\begin{array}{c}\text { Obtenção das autorizações } \\
\text { necessárias ao cumprimento da } \\
\text { legislação de acesso ao patrimônio } \\
\text { genético; responsável pelas } \\
\text { atividades do Plano de Trabalho; e } \\
\text { disponibilizando as estirpes a serem } \\
\text { utilizadas no contrato. }\end{array}$ \\
\hline $\begin{array}{l}\text { Papel do } \\
\text { parceiro } 1\end{array}$ & $\begin{array}{l}\text { Parceiro IMA: Seleção, } \\
\text { tratamento e caracterização de } \\
\text { resíduos agrícolas que podem } \\
\text { ser usados em compostos } \\
\text { de polímero; selecionar os } \\
\text { materiais poliméricos mais } \\
\text { adequados para a preparação } \\
\text { de compósitos. }\end{array}$ & $\begin{array}{c}\text { Parceira AmBev: Realização } \\
\text { de testes de avaliação da } \\
\text { qualidade de malte e cerveja } \\
\text { e validação de desempenho } \\
\text { agronômico de cultivares } \\
\text { registradas em nome da } \\
\text { EMBRAPA. }\end{array}$ & $\begin{array}{c}\text { Parceiro IMAmt: Disponibilizar } \\
\text { recursos humanos para a execução } \\
\text { do contrato, sendo responsável pelo } \\
\text { pagamento das despesas; realização } \\
\text { de contratação de pesquisador; } \\
\text { fazendo compras (consumíveis e } \\
\text { equipamentos) e contratação de } \\
\text { serviços. }\end{array}$ \\
\hline $\begin{array}{l}\text { Papel do } \\
\text { parceiro } 2\end{array}$ & $\begin{array}{l}\text { Parceiro INT: Desenvolvimento de } \\
\text { projetos de embalagens primárias, } \\
\text { secundárias e terciárias na área de } \\
\text { Design. }\end{array}$ & $\begin{array}{c}\text { Parceiro FAPA: Realização de } \\
\text { testes de avaliação de qualidade } \\
\text { de malte e cerveja e validação } \\
\text { de desempenho agronômico de } \\
\text { cultivares registradas em nome da } \\
\text { EMBRAPA e avaliação e testes de } \\
\text { VCU em cepas desenvolvidas pela } \\
\text { EMBRAPA. }\end{array}$ & $\begin{array}{l}\text { Parceiro Comdeagro: Obtenção das } \\
\text { autorizações necessárias para regular o } \\
\text { cumprimento da legislação de acesso ao } \\
\text { patrimônio genético e responsável pela } \\
\text { gestão do processo de obtenção dos } \\
\text { registros dos produtos que vierem a ser } \\
\text { obtidos junto aos órgãos competentes e } \\
\text { produção do bioinseticida. }\end{array}$ \\
\hline
\end{tabular}

Fonte: Dados de pesquisa elaborado pelos autores.

\subsection{Formalização da estrutura de governança de alianças}

Nas alianças analisadas, além da natureza dos atores envolvidos, conectados ou não ao mercado, os parâmetros de formalização também são determinados pelo escopo estratégico das alianças (geração de conhecimento ou inovações para o mercado), prazo (curto, médio ou longo) e natureza das atividades (pesquisa ou desenvolvimento). O Quadro 3 apresenta uma análise da adesão das alianças às proposições relacionadas à formalização da estrutura de governança, destacando os níveis de formalização das instituições parceiras e o objeto da aliança. 


\section{QUADRO 3 ANÁLISE DAS PROPOSIÇÕES VINCULADAS À FORMALIZAÇÃO DA ESTRUTURA DE GOVERNANÇA DAS ALIANÇAS}

\begin{tabular}{|c|c|c|c|}
\hline Proposições: & \multicolumn{3}{|c|}{ Adesão às proposições levantadas } \\
\hline $\begin{array}{c}\text { A formalização da } \\
\text { estrutura de governança } \\
\text { tende a ser: }\end{array}$ & $\begin{array}{l}\text { Aliança } 1 \text { (A1) Embalagem } \\
\text { anatômica para frutas }\end{array}$ & $\begin{array}{c}\text { Aliança } 2 \text { (A2) Cultivar de cevada - BRS } \\
\text { Quaranta }\end{array}$ & $\begin{array}{c}\text { Aliança } 3 \text { (A3) } \\
\text { INOVA-Bti - inseticida biológico }\end{array}$ \\
\hline $\begin{array}{c}\text { (P1) ... alianças } \\
\text { estratégicas entre } \\
\text { instituiçõos públicas de } \\
\text { pesquisa e organizações } \\
\text { conectadas ao mercado. }\end{array}$ & $\begin{array}{c}\text { NÃO APLICÁVEL } \\
\text { Aliança formada entre empresa } \\
\text { pública de pesquisa (EMBRAPA } \\
\text { Agroindústria Alimentar) e } \\
\text { instituições não ligadas ao } \\
\text { mercado (IMA e INT). }\end{array}$ & $\begin{array}{l}\text { ADERENTE } \\
\text { Aliança formada entre empresa } \\
\text { pública de pesquisa (EMBRAPA Trigo) } \\
\text { e parceiro conectado ao mercado } \\
\text { (AmBev). Certificados foram exigidos } \\
\text { para prova de adequação; justificativa } \\
\text { para a escolha do parceiro; } \\
\text { elaboração de plano com informações } \\
\text { sobre atividades, recursos humanos e } \\
\text { financeiros, cronogramas; propriedade } \\
\text { e salvaguardas contratuais e cláusulas } \\
\text { de pagamento de royalties. }\end{array}$ & $\begin{array}{c}\text { ADERENTE } \\
\text { Aliança formada entre empresa } \\
\text { pública de pesquisa (CENARGEN), } \\
\text { um parceiro conectado ao mercado } \\
\text { (Comdeagro) e um parceiro } \\
\text { desconectado (IMAmt). O processo } \\
\text { de formalização da aliança foi } \\
\text { avaliado pelos setores P\&D e T\&T } \\
\text { (Transferência e Tecnologia), } \\
\text { SPAT (Setor de Prospecção } \\
\text { e Avaliação de Tecnologia) e } \\
\text { CTI (Comitê Técnico Interno). } \\
\text { Certificados eram necessários para } \\
\text { provar a adequação; justificativa } \\
\text { para a escolha do parceiro; } \\
\text { propriedade contratual e cláusulas } \\
\text { de salvaguarda; divisão da } \\
\text { porcentagem de royalties. }\end{array}$ \\
\hline $\begin{array}{c}\text { (P2) ... menos formal } \\
\text { quando alianças } \\
\text { estratégicas são } \\
\text { estabelecidas entre } \\
\text { instituições públicas de } \\
\text { pesquisa e organizações } \\
\text { não conectadas ao } \\
\text { mercado. }\end{array}$ & $\begin{array}{c}\text { NÃO ADERENTE } \\
\text { Um plano de atividades foi } \\
\text { desenhado; assinatura de } \\
\text { termos de confidencialidade; } \\
\text { propriedade e salvaguardas } \\
\text { contratuais e cláusulas de } \\
\text { pagamento de royalties. Embora } \\
\text { a aliança envolva parceiros não } \\
\text { ligados ao mercado (IMA e INT), } \\
\text { o escopo era o desenvolvimento } \\
\text { de inovações em embalagens a } \\
\text { médio prazo (5 anos), que exigiu } \\
\text { formalização. }\end{array}$ & $\begin{array}{c}\text { NÃO ADERENTE } \\
\text { Aliança formada entre empresa } \\
\text { pública de pesquisa (EMBRAPA Trigo) } \\
\text { e parceiros ligados ao mercado (FAPA } \\
\text { e AmBev). } 0 \text { escopo era a pesquisa de } \\
\text { cultivares de cevada em longo prazo } \\
\text { (12 anos), que exigia formalização } \\
\text { devido ao resultado das pesquisas e } \\
\text { de parceiros ligados ao mercado. }\end{array}$ & $\begin{array}{c}\text { NÃO ADERENTE } \\
\text { A aliança entre empresa de } \\
\text { pesquisa pública (CENARGEN) } \\
\text { e parceiros não conectados } \\
\text { ao mercado (IMAmt) para o } \\
\text { desenvolvimento de inovação de } \\
\text { produto no curto prazo (1 ano). } \\
\text { No entanto, a formalização é } \\
\text { necessária, devido ao envolvimento } \\
\text { de um parceiro conectado ao } \\
\text { mercado (Comdeagro). }\end{array}$ \\
\hline
\end{tabular}




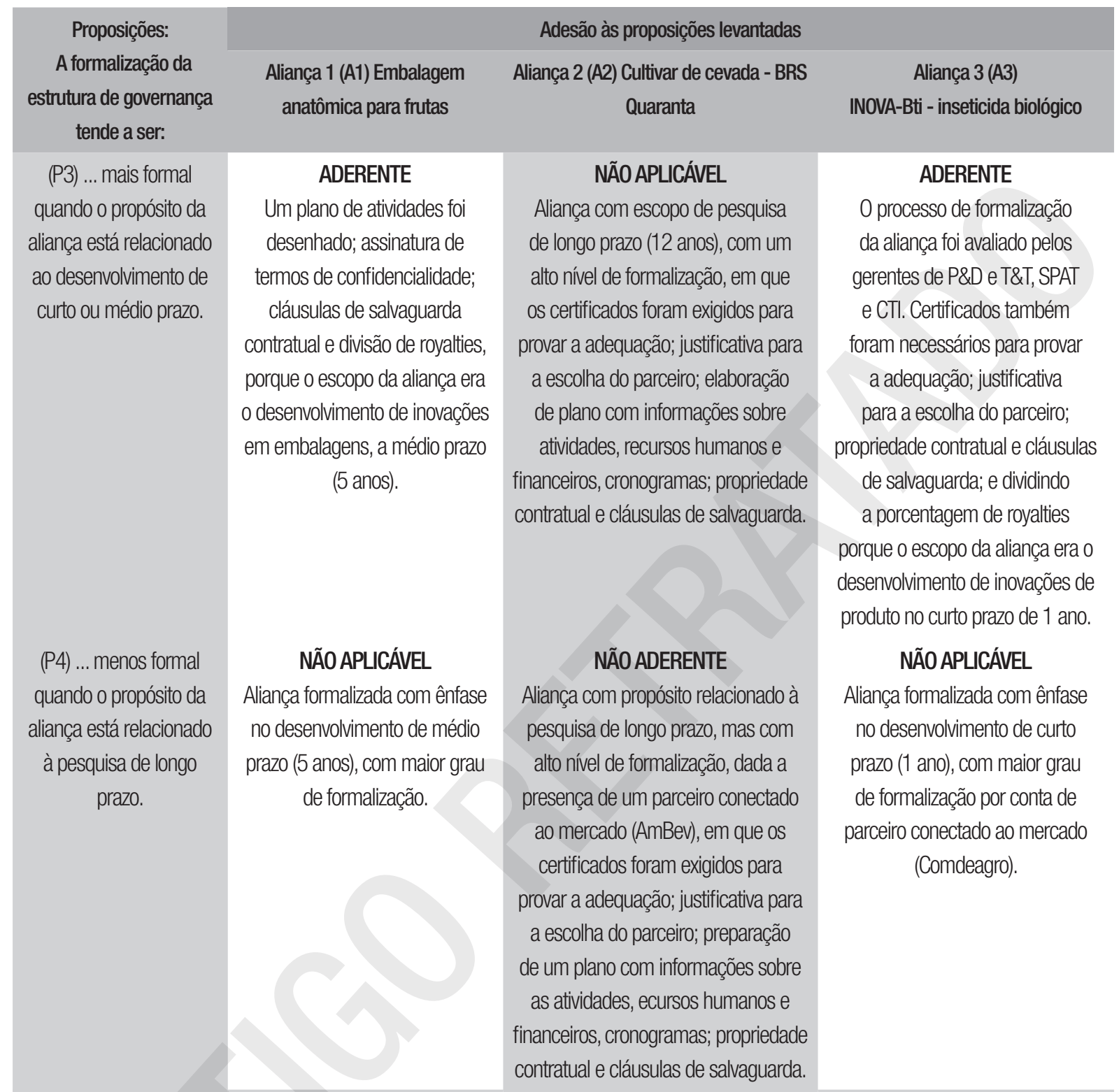

Fonte: Dados de pesquisa elaborado pelos autores.

\subsection{Experiência na formação de alianças estratégicas de P\&D}

O Quadro 4 apresenta uma análise de aderência das alianças às proposições relacionadas à experiência de formação de alianças estratégicas de $\mathrm{P} \& \mathrm{D}$, enfatizando brevemente o empoderamento do CR em alianças com reincidência de parceiros para alianças e em alianças de pesquisa de longo prazo, quando estabelecidas com diferentes parceiros. 


\section{QUADRO 4 ANÁLISE DAS PROPOSIÇÕES SOBRE A EXPERIÊNCIA NO ESTABELECIMENTO DE ALIANÇAS ESTRATÉGICAS DE P\&D}

\begin{tabular}{|c|c|c|c|}
\hline Proposições: & \multicolumn{3}{|c|}{ Aderência às proposições } \\
\hline $\begin{array}{l}\text { Experiencia em estabelecer } \\
\text { alianças estratégicas } \\
\text { quando o objetivo é: }\end{array}$ & A1 & A2 & A3 \\
\hline $\begin{array}{l}\text { (P5) ... pesquisa de longo } \\
\text { prazo, experiência no } \\
\text { estabelecimento de alianças } \\
\text { estratégicas, com diferentes } \\
\text { parceiros, aprimora a CR. }\end{array}$ & $\begin{array}{c}\text { NÃO APLICÁVEL } \\
\text { O objetivo da aliança era o } \\
\text { desenvolvimento de curto } \\
\text { prazo. }\end{array}$ & $\begin{array}{l}\text { ADERENTE } \\
\text { A aliança contou com a participação de } \\
\text { uma grande diversidade de parceiros } \\
\text { (empresa de pesquisa pública, fundação } \\
\text { de pesquisa, indústria, cooperativa e } \\
\text { produtores), cujos distintos conhecimentos } \\
\text { permitiram entender as demandas da } \\
\text { indústria, mercado e produtor; ampliação } \\
\text { da área de abrangência para realização de } \\
\text { pesquisas. }\end{array}$ & $\begin{array}{c}\text { NÃO APLICÁVEL } \\
0 \text { objetivo da aliança era o } \\
\text { desenvolvimento de curto prazo. }\end{array}$ \\
\hline $\begin{array}{c}\text { (P6) ... desenvolvimento } \\
\text { de curto e médio prazo, } \\
\text { experiência na formação } \\
\text { de alianças estratégicas, } \\
\text { com os mesmos parceiros, } \\
\text { potencializa a CR. }\end{array}$ & $\begin{array}{c}\text { ADERENTE } \\
\text { Alianças anteriores já } \\
\text { haviam sido formadas } \\
\text { com os parceiros } \\
\text { envolvidos para } \\
\text { outros projetos. A } \\
\text { repetição fornece maior } \\
\text { conhecimento e confiança } \\
\text { de parceiros e recursos de } \\
\text { parceiros, comunicação } \\
\text { fácil, resultando em maior } \\
\text { velocidade nas atividades. }\end{array}$ & $\begin{array}{l}\text { NÃO APLICÁVEL } \\
\text { O objetivo da aliança é para pesquisas de } \\
\text { longo prazo. }\end{array}$ & $\begin{array}{c}\text { ADERENTE } \\
\text { Parcerias anteriores já haviam } \\
\text { sido firmadas com o parceiro; } \\
\text { atualmente, existem } 21 \text { alianças } \\
\text { entre EMBRAPA e IMAmt; } \\
\text { três pesquisadores do IMAmt } \\
\text { atuam no CENARGEN. A } \\
\text { repetição acelera as atividades } \\
\text { porque conhecem as pessoas, } \\
\text { recursos, conhecimentos, } \\
\text { limitações, questões de valores } \\
\text { e procedimentos internos na } \\
\text { empresa pública de pesquisa. }\end{array}$ \\
\hline
\end{tabular}

Fonte: Dados de pesquisa elaborado pelos autores.

\subsection{Institucionalização de processos da CR}

Com base na análise de CR, identificamos nas alianças em estudo a presença de processos de coordenação interorganizacional, transformação da aliança, aprendizado e pró-atividade (Schilke \& Goerzen, 2010). Em relação aos processos de coordenação, destacamos a utilização de planos de trabalho, que descreviam as atividades de $\mathrm{P} \& \mathrm{D}$ de cada parceiro, a metodologia de trabalho, a previsão de recursos a serem investidos pela parte e o cronograma de atividades. Estes planos de trabalho foram elaborados a partir do compartilhamento de informações prévias de recursos e conhecimento de cada ator envolvido na aliança, e a subsequente divisão de atividades e responsabilidades de cada. Cada ator nomeou um pesquisador para coordenar as atividades, e esforços foram feitos para cumprir esses planos. 
$\mathrm{Na}$ A1, foi criado um comitê, composto por um pesquisador de cada instituição. Os pesquisadores coordenavam as atividades de suas instituições e, em conjunto, monitoravam o andamento das atividades de P\&D das demais instituições, garantindo a sincronização das atividades. Para tanto, ocorreram reuniões mensais e trocas de e-mails, sendo enviados relatórios técnicos e financeiros à agência de fomento semestralmente. Os representantes do comitê visitavam periodicamente os laboratórios de pesquisa, fornecedores de matéria-prima e produtores. O parceiro em A1 era responsável pelo controle financeiro, compras, autorização de viagens e contabilidade da aliança.

A formação da aliança revisou comitês, planejou reuniões, avaliou resultados e compartilhou discussões de estratégia, portanto, considerou rotinas e processos que auxiliaram na coordenação das alianças. Mecanismos de sincronização são necessários para conciliar os interesses individuais de cada instituição e garantir o alinhamento das informações (Gofredo \& Bataglia, 2015) e práticas (Lorenzoni \& Lipparini, 1999) entre os parceiros para garantir a harmonia na busca dos objetivos da aliança, resultando em coordenação eficiente (Gofredo \& Bataglia, 2015) e co-criação de conhecimento (De Silva \& Rossi, 2018).

Em A2, rotinas e processos de coordenação de atividades e gestão de alianças ocorriam por meio de ligações telefônicas e troca constante de e-mails. Os parceiros se reuniam anualmente para sincronizar suas informações. Nessas ocasiões, foram relatadas as atividades já realizadas, planejadas as próximas atividades e elaborado o respectivo relatório. Também foram realizadas visitas aos experimentos, com a participação de representantes de cada instituição parceira. A EMBRAPA assumiu a responsabilidade de iniciar os processos de renovação das alianças, quando as partes manifestassem interesse e apresentassem sugestões.

$\mathrm{Na}$ A3, foram atribuídos, além do gerente técnico, um gerente administrativo, que avaliou o andamento das atividades, e um gerente para controlar a validade do instrumento (pesquisador). As atividades foram sincronizadas por meio de reuniões técnicas, avaliações e relatórios. O pesquisador da parceira da aliança ficou responsável por solicitar a compra de materiais e equipamentos, contratar pessoal para realizar atividades de $\mathrm{P} \& \mathrm{D}$ e prestar contas à instituição. Houve esforços de coordenação por meio de ações explícitas para ajustar as atividades dos parceiros para atingir os objetivos que foram estabelecidos em conjunto, aumentando assim a qualidade relacional, com cooperação na aliança para os resultados (Estrada et al., 2016) e co-criação de conhecimento (De Silva \& Rossi, 2018).

A EMBRAPA apresentou apenas proatividade em A1, buscando potenciais parceiros para complementar sua expertise. Nas Alianças 2 e 3, os parceiros buscaram a EMBRAPA devido ao seu conhecimento científico, experiência em $\mathrm{P} \& \mathrm{D}$ e recursos (laboratórios e materiais genéticos). As Alianças 2 e 3 têm demonstrado proatividade de forma consistente, pois estão sempre em busca de parceiros que possam auxiliar na solução de problemas e no atendimento às demandas do mercado. A proatividade está relacionada à capacidade de reconhecer o contexto do ambiente, identificando as necessidades dos clientes, os segmentos de mercado-alvo ou uma nova oportunidade tecnológica ou de mercado (Teece, 2007) e então tomar a iniciativa de buscar potenciais parceiros para a aquisição de recursos externos (Schilke \& Goerzen, 2010).

Os processos de aprendizagem estão relacionados à capacidade de transferir conhecimento do parceiro da aliança para a instituição (Teece, 2007). Foi identificado uma troca de conhecimento científico e/ou de mercado entre as instituições parceiras. Na A1, a EMBRAPA absorveu o conhecimento específico deste parceiro detentor de expertise na área de polímeros e então transferiu esse aprendizado para outros pesquisadores e equipes de pesquisa por meio de discussões, 
reuniões e apresentações técnicas para que esse conhecimento seja utilizado em outros projetos da EMBRAPA. Por outro lado, o IMA absorveu o conhecimento técnico-científico na área de pós-colheita, transmitindo-o aos alunos e funcionários do laboratório. Essa aliança também resultou em patentes e na publicação de artigos científicos e capítulos de livros, que são meios de transferência de conhecimento para a sociedade.

$\mathrm{Na}$ A2, a EMBRAPA absorveu conhecimento sobre as demandas do mercado de cerveja e qualidade do malte, entendendo as necessidades e a produção de determinadas regiões do Paraná - Brasil. Esse conhecimento foi transferido para a equipe por meio de seminários e palestras. A instituição parceira, por sua vez, adquiriu conhecimento técnico da EMBRAPA de lavouras, controle de doenças, preparo do solo e conservação do solo, e conhecimento geral por meio de dias de campo e reuniões de cevada. Esse conhecimento foi transferido internamente por meio de treinamento de técnicos.

$\mathrm{Na}$ A3, a EMBRAPA adquiriu conhecimento da formulação do produto e do processo de produção. A transferência de conhecimento ocorreu internamente por meio de seminários realizados quinzenalmente para apresentar o andamento dos projetos e seus resultados. O parceiro desta aliança adquiriu conhecimento sobre processos de pesquisa com microrganismos biológicos e controle biológico. Muitos dos recursos buscados nas alianças são conhecimento tácito ou acesso à experiência da empresa parceira (Dyer \& Singh, 1998). Desenvolver a aprendizagem significa que uma instituição tem a capacidade de adquirir, assimilar, transformar e explorar esse conhecimento, melhorando assim o seu desempenho (Zahra \& George, 2002).

Verificamos que mudanças foram necessárias ao longo das alianças, exigindo interação e adaptação entre os parceiros. Nesse sentido, é importante desenvolver rotinas que auxiliem nessas mudanças no decorrer das alianças (Wang \& Rajagopalan, 2015). Em A1, houve mudança de responsabilidade na submissão de patentes. Foi necessário aumentar a quantidade de moldes a serem desenvolvidos, acarretando ajustes financeiros e alterações para a produção das embalagens. $\mathrm{Na}$ A2, ajustes nas cláusulas contratuais e experimentos quantitativos ocorreram no momento da renovação do contrato. A alteração na A3 foi relacionada a ajustes de cronograma devido a atraso na instalação de equipamentos adquiridos no exterior. Mudanças nas alianças são consideradas fenômenos naturais; portanto, é importante que as partes trabalhem juntas para torná-las eficazes e aumentar as chances de desempenho satisfatório em alianças (Reuer \& Zollo, 2000).

O desenvolvimento de uma capacidade depende da repetição contínua de rotinas (Winter, 2003). Assim, quando as instituições estabelecem estruturas organizacionais e contratam especialistas para produzir resultados favoráveis, as rotinas e os procedimentos de gestão das alianças estratégicas de P\&D são institucionalizados (Crossan et al., 1999).

A análise de três alianças mostrou que todas elas têm rotinas e processos de CR institucionalizados. As instituições adotam rotinas, processos e mecanismos formalizados e replicáveis para a coordenação de alianças de P\&D. As instituições também demonstraram capacidade de aprender com o conhecimento específico de suas instituições parceiras ou conhecimento gerado e transferido por meio da aliança. As instituições também se mostraram flexíveis (em termos de transformação) nas mudanças e houve processos pró-ativos na EMBRAPA Agroindústria Alimentar, FAPA e IMAmt. No entanto, esses processos não se mostraram sistematizados na EMBRAPA Trigo, CENARGEN e IMA, conforme destacado no Quadro 5 (proposição não aderente). 


\section{QUADRO 5 ANÁLISE DE PROPOSIÇÕES VINCULADAS À INSTITUCIONALIZAÇÃO DE PROCESSOS DE CR}

\begin{tabular}{|c|c|c|c|c|}
\hline \multirow{2}{*}{\multicolumn{2}{|c|}{$\begin{array}{l}\text { Proposições vinculadas } \\
\text { à institucionalização de } \\
\text { processos de CR }\end{array}$}} & \multicolumn{3}{|c|}{ Aderência a proposições } \\
\hline & & A1 & A2 & A3 \\
\hline $\begin{array}{l}\text { (P7) À medida que } \\
\text { as organizações } \\
\text { institucionalizam } \\
\text { processos de } \\
\text { coordenação } \\
\text { interorganizacional, } \\
\text { proatividade } \\
\text { em alianças, } \\
\text { aprendizagem } \\
\text { organizacional e } \\
\text { transformação } \\
\text { de alianças, } \\
\text { mais madura é } \\
\text { a capacidade } \\
\text { relacional. }\end{array}$ & 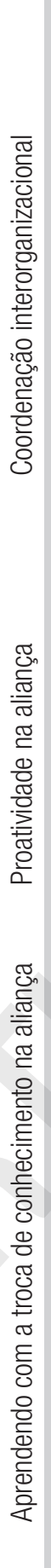 & $\begin{array}{c}\text { ADERENTE } \\
\text { A EMBRAPA buscou potenciais } \\
\text { parceiros para complementar sua } \\
\text { expertise. } \\
\text { ADERENTE } \\
\text { Absorção de conhecimento técnico- } \\
\text { científico na área de polímeros } \\
\text { e pós-colheita; transferência de } \\
\text { conhecimento para equipes de } \\
\text { pesquisa por meio de discussões, } \\
\text { reuniões e apresentações técnicas; } \\
\text { aos alunos e funcionários do } \\
\text { laboratório por meio do ensino e da } \\
\text { publicação de artigos científicos, } \\
\text { capítulos de livros e registro de } \\
\text { patentes. }\end{array}$ & 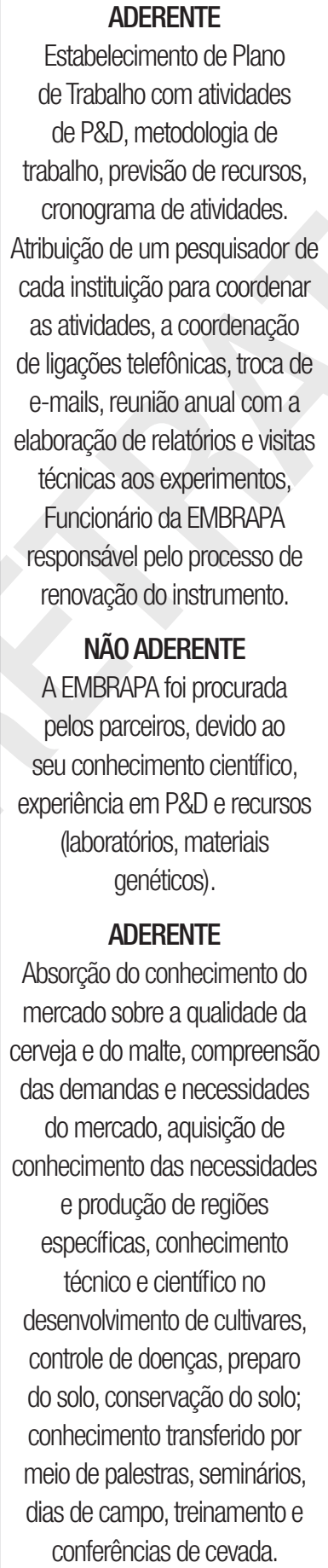 & $\begin{array}{c}\text { ADERENTE } \\
\text { Estabelecimento de Plano de } \\
\text { Trabalho com atividades de P\&D, } \\
\text { metodologia de trabalho, previsão de } \\
\text { recursos, cronograma de atividades. } \\
\text { Atribuição de um pesquisador de } \\
\text { cada instituição para coordenar } \\
\text { as atividades, atribuição de um } \\
\text { gerente administrativo para avaliar } \\
\text { o andamento das atividades, e } \\
\text { um gerente para controlar sua } \\
\text { validade. Reuniões, avaliações } \\
\text { técnicas e relatórios. Atribuição de } \\
\text { um parceiro para adquirir materiais, } \\
\text { equipamentos e contratar pessoal } \\
\text { para atividades de P\&D. } \\
\text { NÃO ADERENTE } \\
\text { A EMBRAPA foi procurada } \\
\text { por parceiros devido ao seu } \\
\text { conhecimento científico, experiência } \\
\text { em P\&D e recursos (laboratórios, } \\
\text { materiais genéticos). } \\
\text { ADERENTE } \\
\text { Absorção de formulação e } \\
\text { conhecimento de produção, } \\
\text { conhecimentos relacionados } \\
\text { microrganismos biológicos e } \\
\text { de controle biológico, transferência } \\
\text { seminários. }\end{array}$ \\
\hline
\end{tabular}




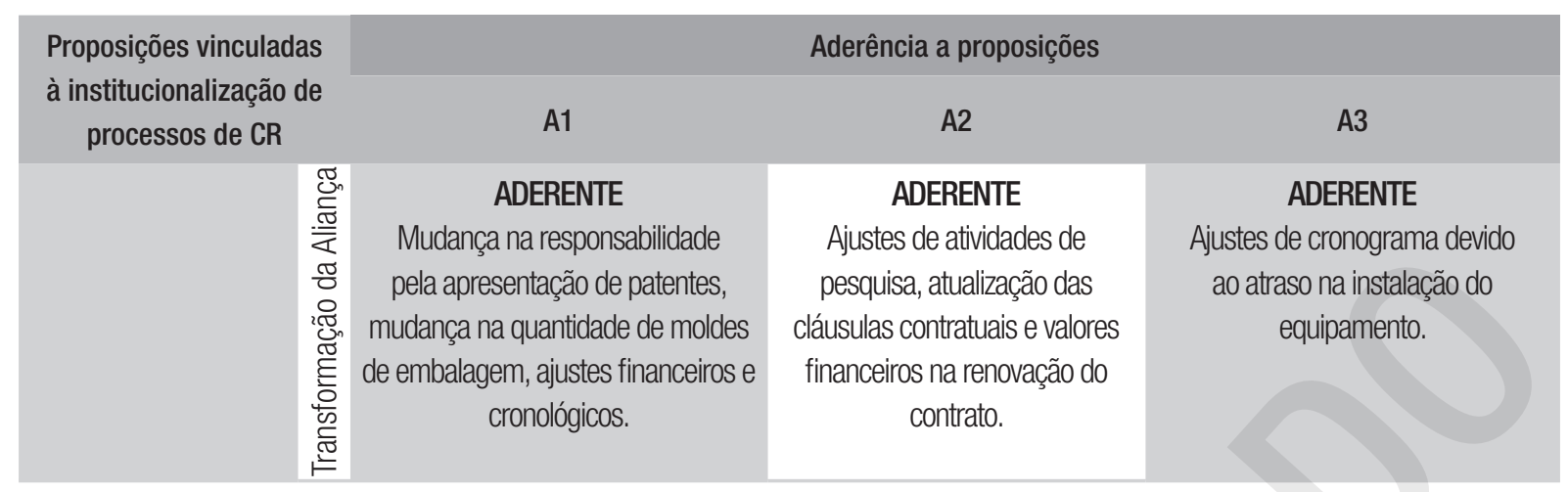

Fonte: Dados de pesquisa elaborado pelos autores.

\subsection{Transbordamento de capacidade relacional}

As instituições buscam alianças orientadas por competências para melhorar seus recursos internos (acesso a recursos complementares) e conhecimento interno (por meio de aprendizagem organizacional e criação de conhecimento) (Lin \& Darnall, 2015) e são, portanto, mais propensos a buscar parceiros diversificados e intersetoriais (Walsh et al., 2016).

Constatou-se nas três alianças que cada instituição parceira possuía conhecimentos e recursos específicos e estava motivada a formar alianças para agregar ativos, diferentes capacidades e habilidades para atingir seus objetivos. Tanto nas unidades da EMBRAPA quanto em seus parceiros não conectados ao mercado (IMA e IMAmt), identificamos expertise na realização de atividades de pesquisa, como o parceiro em A1 e IMA, um instituto com expertise em pesquisa de polímeros. Por outro lado, parceiros ligados ao mercado (AmBev e Comdeagro) possuem maior conhecimento das demandas do setor, pois estão sempre buscando desenvolver inovações para atender às demandas. Encontramos um transbordamento de processos dessas alianças de uma instituição para outra e desenvolvimento (de parceiros vinculados ou não ao mercado à EMBRAPA), resultando em melhorias ou novas práticas.

$\mathrm{Na}$ A1, a partir dos conhecimentos adquiridos na EMBRAPA Agroindústria Alimentar, relacionados às rotinas e processos inerentes à pesquisa pós-colheita, IMA desenvolveu uma linha de pesquisa para embalagens, estabelecendo o fluxo do processo. $\mathrm{Na} \mathrm{A} 2$, com base no conhecimento inerente à FAPA eàs atividades de pesquisa de mercado da AmBev, a EMBRAPA adaptou uma metodologia de P\&D para o desenvolvimento de cevada e outros cereais através do conhecimento das demandas da indústria, como qualidade do malte (AmBev) e clima. No início de A2 com a EMBRAPA, 100\% das cultivares de cevada utilizadas eram oriundas de alianças com a EMBRAPA. Hoje, a FAPA usa 50\%, que foram desenvolvidos em alianças com outras instituições. Verificou-se também que a FAPA adaptou as cláusulas contratuais, de acordo com os modelos adotados na pesquisa realizada pela EMBRAPA. Assim, podemos inferir que, a partir dessa aliança, a instituição passou a utilizar rotinas e processos da EMBRAPA para P\&D.

Em A3, com base nas dificuldades encontradas pelos órgãos reguladores para a produção deste tipo de produto, A EMBRAPA desenvolveu um documento regulatório de requisitos essenciais para a criação de alianças para o desenvolvimento de produtos similares. Como o parceiro possui expertise em formulação e produção, a EMBRAPA incorporou, adaptou, e passou a utilizar rotinas e processos de formulação e produção de produtos similares. Comdeagro, por sua vez, construiu a planta de produção de bioinseticidas a partir de conhecimentos, rotinas e processos que já existiam em laboratórios de biotecnologia, devido à expertise adquirida pelo CENARGEN em biotecnologia. Os funcionários da 
Comdeagro participaram de treinamentos na EMBRAPA. As análises de transbordamento das rotinas e processos de $\mathrm{P} \& \mathrm{D}$, de acordo com o parceiro, são apresentadas no Quadro 6.

\section{QUADRO 6 ANÁLISE DAS PROPOSIÇÕES VINCULADAS AO TRANSBORDAMENTO DE CR}

\begin{tabular}{|c|c|c|c|}
\hline \multirow{2}{*}{$\begin{array}{l}\text { Propostas vinculadas ao } \\
\text { transbordamento de CR }\end{array}$} & \multicolumn{3}{|c|}{ Aderência a proposições } \\
\hline & A1 & $\mathrm{A} 2$ & A3 \\
\hline $\begin{array}{l}\text { (P8) Em alianças estratégicas } \\
\text { de P\&D, processos inerentes } \\
\text { à pesquisa são transferidos da } \\
\text { empresa de pesquisa pública } \\
\text { para os parceiros (conectado ou } \\
\text { não conectado). }\end{array}$ & $\begin{array}{c}\text { ADERENTE } \\
\text { Desenvolvimento de linha } \\
\text { de pesquisa no IMA para } \\
\text { embalagens com a adoção das } \\
\text { rotinas e processos de pesquisa } \\
\text { da EMBRAPA. }\end{array}$ & $\begin{array}{c}\text { ADERENTE } \\
\text { A FAPA diversificou a pesquisa e } \\
\text { a procedência das cultivares de } \\
\text { cevada e adaptou as cláusulas } \\
\text { contratuais, de acordo com os } \\
\text { modelos adotados nas pesquisas } \\
\text { realizadas pela EMBRAPA. }\end{array}$ & $\begin{array}{l}\text { ADERENTE } \\
\text { A Comdeagro construiu uma } \\
\text { fábrica para a produção de } \\
\text { bioinseticida, com base em } \\
\text { orientação para pesquisa e } \\
\text { treinamento ministrado pela } \\
\text { EMBRAPA. }\end{array}$ \\
\hline $\begin{array}{l}\text { (P9) Em alianças estratégicas } \\
\text { de P\&D, processos inerentes ao } \\
\text { desenvolvimento são transferidos } \\
\text { de parceiros (conectado ou } \\
\text { não conectado) à empresa de } \\
\text { pesquisa pública. }\end{array}$ & $\begin{array}{c}\text { NÃO APLICÁVEL } \\
\text { Aliança formada com instituição } \\
\text { não ligada ao mercado com } \\
\text { expertise em pesquisa de } \\
\text { polímeros. }\end{array}$ & $\begin{array}{c}\text { ADERENTE } \\
\text { Adaptação na EMBRAPA da } \\
\text { metodologia de P\&D para o } \\
\text { desenvolvimento da cevada, } \\
\text { resultante do conhecimento das } \\
\text { demandas da indústria (AmBev) e } \\
\text { clima e produtores das regiões do } \\
\text { Estado do Paraná obtido na FAPA. }\end{array}$ & $\begin{array}{l}\text { ADERENTE } \\
\text { Utilização de rotinas de } \\
\text { formulação e produção } \\
\text { de produtos similares da } \\
\text { EMBRAPA que foram da } \\
\text { expertise da Comdeagro. }\end{array}$ \\
\hline
\end{tabular}

Fonte: Dados de pesquisa elaborado pelos autores.

\section{MODELO INTERORGANIZACIONAL PROPOSICIONAL}

Com base no estudo aprofundado das alianças que geram inovações agrícolas, desenvolvemos um modelo interorganizacional proposicional baseado em uma comparação teórico-empírica, envolvendo uma empresa pública de pesquisa e seus parceiros ligados e não ligados ao mercado. O modelo é dividido em seis blocos, que representam categorias de análise da CR evidenciadas empiricamente, incluindo: (Bloco 1) Estrutura de governança; (Bloco 2) Experiência de aliança; (Bloco 3) Amadurecimento da CR; (Bloco 4) transbordamento da CR; (Bloco 5) Resultados; e (Bloco 6) Facilitador.

O Bloco 1 representa a formalização da estrutura de governança, que é mais formalizada se um dos parceiros da aliança estiver conectado ao mercado, independentemente se a natureza das atividades de pesquisa é o desenvolvimento de longo ou curto ou médio prazo. Além disso, essa formalização é maior se o escopo da aliança for a geração de inovações que podem resultar em royalties (Figura 1).

O Bloco 2, por outro lado, representa a reincidência de parceiros como um potencial para a CR quando a natureza da atividade é de desenvolvimento, pois permite um maior conhecimento dos recursos do parceiro, exatidão dos custos das atividades, e baixa incidência de conflitos e maior agilidade no alcance dos resultados. A experiência com diversos parceiros, com diferentes conhecimentos científicos e de mercado, permite obter resultados de pesquisas, contribuindo para a geração de inovação (exemplo: cultivar de cevada "Quaranta"). Também foi descoberto que a experiência individual dos pesquisadores pode melhorar a CR da instituição, uma vez que todos os pesquisadores entrevistados relataram ter experiência na formação de alianças, auxiliando os processos de coordenação, aprendizagem, pró-atividade, transformação e relações interpessoais (Figura 1). 


\section{FIGURA 1 MODELO INTERORGANIZACIONAL PARA GERAÇÃO DE INOVAÇÕES A PARTIR DE ALIANÇAS ESTRATÉGICAS DE P\&D COM BASE NA EVIDÊNCIA EMPÍRICA DOS PROCESSOS DE CR DA EMBRAPA E SEUS PARCEIROS EXTERNOS}

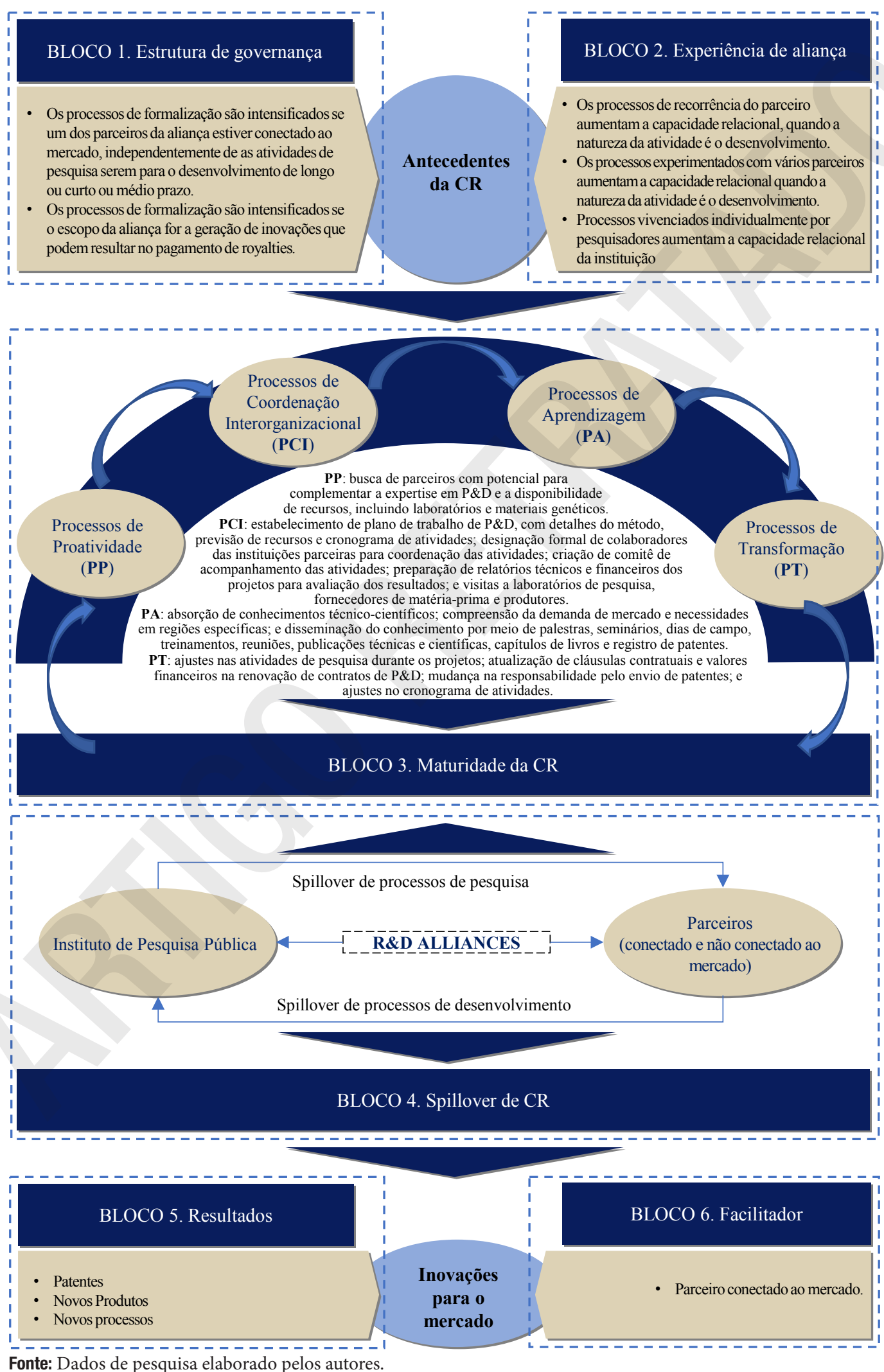

Fonte: Dados de pesquisa elaborado pelos autores. 
O bloco 3, com base em evidências empíricas, mostra que quanto mais institucionalizado é um conjunto de processos de gestão estratégica de alianças de $\mathrm{P} \& \mathrm{D}$ em uma empresa pública de pesquisa, quanto mais institucionalizado for a $\mathrm{CR}$, e seus processos constitutivos poderão ser replicáveis e adaptáveis em futuras alianças (Figura 1). Destaca-se um conjunto de processos que podem conferir maturidade a CR:

a) Processos de coordenação interorganizacional: estabelecimento de um plano de trabalho de $\mathrm{P} \& \mathrm{D}$, detalhando o método, previsão de recursos e cronograma de atividades; designação formal de colaboradores das instituições parceiras para coordenação das atividades; criação de comitê de acompanhamento das atividades; elaboração de relatórios técnicos e financeiros de projetos para avaliação de resultados; e visitas a laboratórios de pesquisa, fornecedores de matérias-primas e produtores;

b) Processos de pro atividade na aliança: procurar parceiros com potencial para complementar a experiência em $\mathrm{P} \& \mathrm{D}$ e a disponibilidade de recursos, incluindo laboratórios e materiais genéticos;

c) Aprendizagem: absorção de conhecimento técnico e científico; compreensão das demandas e necessidades do mercado em regiões específicas; e disseminação do conhecimento por meio de palestras, seminários, dias de campo, treinamentos, reuniões, publicações técnicas e científicas, capítulos de livros e registro de patentes;

d) Transformação: ajustar as atividades de pesquisa durante os projetos; atualização de cláusulas contratuais e valores financeiros efetuados na renovação de contratos de $\mathrm{P} \& \mathrm{D}$; mudança de responsabilidade pela submissão de patentes; e ajustes no cronograma de atividades.

Quando uma instituição consegue desenvolver e, portanto, institucionalizar este conjunto de processos de gestão estratégica de alianças de $\mathrm{P} \& \mathrm{D}$, conferindo maturidade à $\mathrm{CR}$, há um transbordamento de processos de pesquisa e desenvolvimento entre a empresa pública de pesquisa e parceiros conectados e não conectados ao mercado (Figura 1).

Em relação ao transbordamento de processos (Bloco 4), em alianças com ambos os escopos (pesquisa e desenvolvimento), há transbordamento dos processos de pesquisa da empresa pública de pesquisa (devido à expertise científica) para os parceiros (conectados e não conectados ao mercado). Por outro lado, em relação aos processos de desenvolvimento, há transbordamento de ambos os parceiros (conectado e não conectado) à empresa de pesquisa pública, resultando na melhoria de seus processos ou na adoção de novas práticas de desenvolvimento (Figura 1). Assim, destaca-se o transbordamento dos seguintes processos de P\&D:

a) Transbordamento de processos de desenvolvimento: (1) Diversificação de produtos e processos já existentes na empresa pública, referência em pesquisa após estabelecimento de aliança com parceiro atento às necessidades regionais; (2) Adoção de novos padrões de qualidade na empresa pública, referência em pesquisa após formação de aliança com parceiro atento às necessidades industriais; (3) Implementação de documento regulatório de requisitos essenciais para P\&D colaborativo na empresa pública após formação de aliança com parceiro com maior expertise em salvaguardas contratuais;

b) Transbordamento de processos de pesquisa: (1) Implantação de nova linha de pesquisa na empresa parceira após o estabelecimento de alianças com a EMBRAPA, referência em pesquisa; 
(2) Após o estabelecimento de alianças com a EMBRAPA, o parceiro incorpora conhecimentos que possibilitam a produção do produto inovador; (3) Após as alianças, funcionários da empresa parceira deram continuidade ao treinamento em pesquisa na empresa pública.

Por fim, a partir dos Blocos 5 e 6 do modelo interdisciplinar proposicional, a CR potencializa o desenvolvimento de produtos, processos, patentes, etc. e, posteriormente, inovações para o mercado. O modelo (Figura 1) também mostra que se produtos, processos e patentes são desenvolvidos em alianças com pelo menos um parceiro de mercado, são lançados no mercado com mais rapidez, tornando-se inovações, pois os parceiros de mercado possuem maior expertise em comercialização ou geração de inovações.

\section{CONSIDERAÇÕES FINAIS}

As inovações agrícolas desempenham um papel importante diante das perspectivas de aumento contínuo da população e da recorrência dos problemas climáticos. Assim, conduzindo P\&D para o desenvolvimento de inovações que contribuam para o aumento da produtividade agrícola, controle de pragas ou adaptações climáticas são ações valiosas e cruciais para garantir a segurança alimentar. Nas últimas décadas, alianças estratégicas têm sido consideradas uma alternativa às instituições, no que diz respeito à realização de $\mathrm{P} \& \mathrm{D}$ e geração de inovações. A capacidade relacional, que tem forte relevância neste processo, pode afetar diretamente o desempenho de alianças estratégicas, o que leva à necessidade de estudá-la mais a fim de usá-la de forma mais produtiva dentro das organizações.

Assim, este estudo buscou respostas para a seguinte questão: "Como a capacidade relacional contribui para a geração de inovações agrícolas desenvolvidas em alianças estratégicas de P\&D, estabelecidas entre a EMBRAPA e parceiros externos?" Para respondê-la e chegar a algumas propostas desenvolvidas a partir do tema, foram estudadas em profundidade três alianças estratégicas, formadas entre as Unidades da EMBRAPA e parceiros externos.

Constatou-se que a EMBRAPA e a experiência de seus parceiros externos em alianças estratégicas de $\mathrm{P} \& \mathrm{D}$ potencializaram a CR. Todas as Unidades e parceiros da EMBRAPA possuem experiência na construção de alianças. A reincidência de parceiros também potencializou a CR nas alianças, com ênfase no desenvolvimento, uma vez que possibilita maior conhecimento dos recursos dos parceiros, maior precisão dos custos da atividade, menor incidência de conflitos, e maior agilidade na obtenção de resultados. Em aliança com ênfase na pesquisa, vivência com diversos parceiros e diferentes conhecimentos potencializados CR, levando à geração de inovação.

Quando as instituições têm e desenvolvem as dimensões e fatores que capacitam a CR, há transbordamento de rotinas e processos inerentes à pesquisa e desenvolvimento entre a EMBRAPA e seus parceiros externos em alianças estratégicas de P\&D. Em alianças com os dois escopos, pesquisa e desenvolvimento, houve transbordamento de rotinas e processos de pesquisa da EMBRAPA (devido à expertise científica) ao parceiro (conectado ou não ao mercado) e do parceiro (conectado ou não ao mercado) à EMBRAPA, resultando na melhoria de rotinas e processos ou na adoção de novas práticas.

Unidades da EMBRAPA e parceiros externos têm as dimensões de coordenação, aprendizagem e transformação de CR institucionalizado (formalizado e replicável em futuras alianças). A proatividade, também parte do construto CR, ficou evidente em uma Unidade da EMBRAPA (Agroindústria de 
Alimentos) e em dois parceiros (FAPA e IMAmt). Podemos considerar essas dimensões maduras, ou formalizadas, nessas instituições e, portanto, passíveis de replicação em futuras alianças.

No que diz respeito ao aspecto econômico da inovação, a embalagem anatômica para frutas ainda tem potencial para ser lançada e comercializada. Isso ainda não ocorreu devido à ausência de um parceiro de marketing nos estágios iniciais de P\&D. Quando instituições ligadas ao mercado (empresas ou cooperativas) não participam, é mais difícil um produto ou processo ser bem recebido pelo mercado ou atingir uma taxa adequada de royalties em relação ao investimento. Nas outras alianças em questão (cerveja de cevada e inseticida biológico), identificou-se uma conexão com o mercado por meio dos parceiros, como cooperativas e empresas, mostrando que as inovações decorrentes dessas alianças já tiveram impactos econômicos, sociais e ambientais.

Este estudo contribui para o avanço do conhecimento em alianças de P\&D em termos de experiência, como estudos anteriores já haviam afirmado a importância da experiência acumulada e do reaproveitamento de parceiros para o desenvolvimento de CR e maiores chances de sucesso em futuras alianças (Kohtamäki, Rabetino, \& Möller, 2018). No entanto, constatou-se que o reaproveitamento de parceiros na verdade fortalece a CR, quando ocorrem em alianças de $\mathrm{P} \& \mathrm{D}$ no desenvolvimento. Para alianças de P\&D em pesquisa, a experiência com uma maior diversidade de parceiros de diferentes naturezas (conectados e não conectados ao mercado) potencializa a CR.

Este estudo também contribui para o campo da estrutura de governança. Os mecanismos utilizados devem ser utilizados de forma adequada para evitar comportamentos oportunistas e aumentar o nível de confiança entre os parceiros; entretanto, ao mesmo tempo, os mecanismos devem ser usados de forma flexível para não reduzir a produção inovadora de atividades de P\&D. Este resultado está de acordo com os achados de estudos recentes (Milagres et al., 2017; Sumo, Weele, \& Duysters, 2016). Por um lado, a estrutura de governança da aliança pode melhorar seu desempenho. Por outro lado, pode resultar em maior ênfase nos processos e na burocracia, reduzindo a autonomia dos parceiros, prejudicando a agilidade e customização dos objetivos da aliança.

Outras contribuições para o avanço do conhecimento foram a institucionalização e o transbordamento, culminando em um modelo proposicional. Em alianças de P\&D, quando os parceiros desenvolveram CR, eles são capazes de transbordar de conhecimentos, rotinas e processos de pesquisa (instituto de pesquisa público para parceiro) e desenvolvimento (parceiro para instituto de pesquisa público), melhorando seus processos e rotinas ou adotando novas práticas. Da mesma forma, quanto mais institucionalizadas as rotinas e processos de $\mathrm{CR}$, mais maduros e replicáveis para outras alianças.

Para gestores de instituições de $\mathrm{P} \& \mathrm{D}$, estejam ou não ligadas ao mercado, o estudo indica que quando são formadas alianças de $\mathrm{P} \& \mathrm{D}$, com ênfase no desenvolvimento de inovações, os parceiros recorrentes de outras alianças estas poderiam potencializar a CR, levando ao desenvolvimento de inovações mais ágil. Por outro lado, quando instituições não mercantis procuram parceiros para alianças de $\mathrm{P} \& \mathrm{D}$, para o desenvolvimento da inovação, é importante que pelo menos um parceiro esteja conectado ao mercado, com potencial capacidade de produção futura. Desta forma, os gestores precisam ter um papel ativo na escolha dos parceiros, de acordo com a ênfase da aliança, para atingir os objetivos e os melhores resultados possíveis da aliança.

Esta pesquisa é qualitativa; assim, é limitado pela seleção restrita do número de casos. Consequentemente, não pode ser generalizado para outras alianças de $\mathrm{P} \& \mathrm{D}$ ou desenvolvimento de inovações, nem seus resultados podem ser generalizados em relação a outras unidades da EMBRAPA 
RAP | Capacidade relacional: um estudo da Empresa Brasileira de Pesquisa Agropecuária

e seus parceiros. Destaca-se que a validade da inferência causal neste tipo de pesquisa depende do uso e operacionalização de variáveis, condições ou mecanismos que são gerais (e não específicos).

Também foi possível identificar que, em alianças de $\mathrm{P} \& \mathrm{D}$ para o desenvolvimento de inovações agrícolas, pesquisadores da EMBRAPA e dos parceiros, que atuam diretamente nas atividades de P\&D, desempenham um papel importante na coordenação das atividades e nas relações interorganizacionais. Os pesquisadores são canais através dos quais as alianças são formadas, à medida que emergem de sua rede de contatos e por causa de sua experiência individual em alianças, o que também contribui para seu sucesso. Assim, estudos futuros poderão analisar a influência da CR dos indivíduos na CR da instituição em alianças estratégicas de $\mathrm{P} \& \mathrm{D}$ para gerar inovações agrícolas. Além disso, sugerimos estender a análise a um maior número de instituições que formaram alianças estratégicas de P\&D na agricultura. 


\section{REFERÊNCIAS}

Appio, F. P., Martini, A., Petruzzelli, A. M., Neirotti, P., \& Van Looy, B. (2017). Search mechanisms and innovation: An analysis across multiple perspectives. Technological Forecasting \& Social Change, 120, 103-116.

Ariño, A., Reuer, J. J., Mayer, K. J., \& Jané, J. (2014). Contracts, negotiation, and learning: An examination of termination provisions. Journal of Management Studies, 51(3), 379-405.

Collis, J., \& Hussey, R. (2005). Pesquisa em Administração: um guia prático para alunos de graduação e pós-graduação. (2nd. ed). Porto Alegre, RS: Bookman.

Costa, P. R., \& Porto, G. S. (2014). Technological governance and cooperability in Brazilian multinationals. Revista de Administração de Empresas, 54(2), 201-221.

Creswell, J. (2017). Research design: Qualitative, quantitative, and mixed methods approaches. London, UK: SAGE publications.

Crossan, M. M., Lane, H. W., \& White, R. E. (1999). An organizational learning framework: From intuition to institution. Academy of management review, 24(3), 522-537.

De Almeida, J. M. S., Costa, P. R. (2017). Development of relational capability in technology-based companies in the information and communication technology sector. International Journal of Managerial Studies and Research (IJMSR), 5(4), 119-126.

De Silva, M., \& Rossi, F. (2018). The effect of firms' relational capabilities on knowledge acquisition and co-creation with universities. Technological Forecasting and Social Change, 133, 72-84.

Ding, R., Dekker, H. C., \& Groot, T. (2013). Risk, partner selection and contractual control in interfirm relationships. Management Accounting Research, 24(2), 140-155

Donada, C., Nogatchewsky, G., \& Pezet, A. (2015). Understanding the relational dynamic capabilitybuilding process. Strategic Organization, 14(2), 93-117.

Du, J., Leten, B., \& Vanhaverbeke, W. (2014). Managing open innovation projects with science- based and market-based partners. Research Policy, 43(5), 828-840.

Dyer, J. H., \& Singh, H. (1998). The relational view: Cooperative strategy and sources of interorganizational competitive advantage. Academy of management review, 23(4), 660-679.

Estrada, I., Faems, D., Cruz, N. M., \& Santana, P. P. (2016). The role of interpartner dissimilarities in Industry-University alliances: Insights from a comparative case study. Research Policy, 45(10), 2008-2022.

Etzkowitz, H. (2017). Innovation Lodestar: The entrepreneurial university in a stellar knowledge firmament. Technological Forecasting and Social Change, 123, 122-129.

Godoy, A. S. (1995). Pesquisa qualitativa: tipos fundamentais. Revista de Administração de Empresas, 35(3), 20-29.

Gofredo, T. R., \& Bataglia, W. (2015). Os mecanismos de sincronização em alianças estratégicas. Revista de Administração da Universidade Federal de Santa Maria, 8(4), 633-649.

Gulati, R., Lawrence, P. R., \& Puranam, P. (2005). Adaptation in vertical relationships: Beyond incentive conflict. Strategic Management Journal, 26(5), 415-440.

Heimeriks, K. H., \& Duysters, G. (2007). Alliance capability as a mediator between experience and alliance performance: an empirical investigation into the alliance capability development process. Journal of Management Studies, 44(1), 25-49.

Helfat, C. E., Finkelstein, S., Mitchell, W., Peteraf, M., Singh, H., Teece, D., ... Winter, S. G. (2009). Dynamic capabilities: Understanding strategic change in organizations. Oxford, UK: Blackwell.

Hoang, H., \& Rothaermel, F. T. (2005). The effect of general and partner-specific alliance experience on joint R\&D project performance. Academy of Management Journal, 48(2), 332-345.

Johnsen, R. E., \& Ford, D. (2006). Interaction capability development of smaller suppliers in relationships with larger customers. Industrial Marketing Management, 35(8), 1002-1015.

Kauppila, O. P. (2015). Alliance management capability and firm performance: Using resource- 
based theory to look inside the process black box. Long Range Planning, 48(3), 151-167.

Kohtamäki, M., Rabetino, R., \& Möller, K. (2018). Alliance capabilities: A systematic review and future research directions. Industrial Marketing Management, 68, 188-201.

Lhuillery, S., \& Pfister, E. (2009). R\&D cooperation and failures in innovation projects: Empirical evidence from French CIS data. Research Policy, 38(1), 45-57.

Lin, H., \& Darnall, N. (2015). Strategic alliance formation and structural configuration. Journal of Business Ethics, 127(3), 549-564.

Lorenzoni, G., \& Lipparini, A. (1999). The leveraging of interfirm relationships as a distinctive organizational capability: a longitudinal study. Strategic Management Journal, 20(4), 317-338.

Lundvall, B. A. (1988). Innovation as an interactive process: From user-producer interaction to the National System of Innovation. In G. Dosi, C. Freeman, R. Nelson, G. Silverberg \& L. Soete. (Eds.), Technical change and economic theory (Chap. 11, pp. 349-369). London, UK: Pinter Publishers.

Marconi, M. de A., \& Lakatos, E. M. (2006). Técnicas de pesquisa (6. ed, Vol. 4). São Paulo, SP: Atlas.

Milagres, R., Rezende, O., \& Silva, S. A. G. D. (2017). Papel e posição do departamento de alianças: caso EMBRAPA. Revista de Administração Pública, 51(3), 431-450.

Minayo, M. de S., \& Sanches, O. (1993). Quantitativoqualitativo: oposição ou complementaridade. Cadernos de saúde pública, 9(3), 239-262.

Niesten, E., \& Jolink, A. (2015). The impact of alliance management capabilities on alliance attributes and performance: a literature review. International Journal of Management Reviews, 17(1), 69-100.

Patterson, W., \& Ambrosini, V. (2015). Configuring absorptive capacity as a key process for research intensive firms. Technovation, 36, 77-89.

Reuer, J., \& Zollo, M. (2000). Managing governance adaptations in strategic alliances. European Management Journal, 18(2), 164-172.

Rodríguez-Díaz, M., \& Espino-Rodríguez, T. F. (2006). Redesigning the supply chain: reengineering, outsourcing, and relational capabilities. Business Process Management Journal, 12(4), 483-502.

Shakeri, R., \& Radfar, R. (2017). Antecedents of strategic alliances performance in biopharmaceutical industry: A comprehensive model. Technological Forecasting and Social Change, 122, 289-302.

Schilke, O., \& Goerzen, A. (2010). Alliance management capability: an investigation of the construct and its measurement. Journal of Management, 36(5), 1192-1219.

Sorrentino, F., \& Garraffo, F. (2012). Explaining performing R\&D through alliances: Implications for the business model of Italian dedicated biotech firms. Journal of Management \& Governance, 16(3), 449-475.

Sumo, R., Valk, W., Weele, A., \& Duysters, G. (2016). How Incomplete Contracts Foster Innovation in Inter-Organizational Relationships. European Management Review, 13(3), 179-192.

Teece, D. J. (2007). Explicating dynamic capabilities: the nature and microfoundations of (sustainable) enterprise performance. Strategic Management Journal, 28(13), 1319-1350.

Walsh, J. P., Lee, Y.-N., \& Nagaoka, S. (2016). Openness and innovation in the US: Collaboration form, idea generation and implementation. Research Policy, 45(8), 1660-1671.

Wang, Y., \& Rajagopalan, N. (2015). Alliance capabilities review and research agenda. Journal of Management, 41(1), 236-260.

Winter, S. G. (2003). Understanding dynamic capabilities. Strategic Management Journal, 24(10), 991-995.

Zamberlan, L., Rasia, P. C., Souza, J. D. S., Grison, A. J., Gagliardi, A. O., Teixeira, E. B., ... Allebrandt, S. L. (2014). Pesquisa em ciências sociais aplicadas. Ijuí, RS: Editora Unijuí.

Zhang, S., Li, N., \& Li, J. (2017). Redefining relational rent. Technological Forecasting and Social Change, 117, 315-326.

Zollo, M., Reuer, J. J., \& Singh, H. (2002). Interorganizational routines and performance in strategic alliances. Organization Science, 13(6), 701-713. 


\section{Taísa Scariot Preusler}

https://orcid.org/0000-0002-0136-9040

Mestre em Administração de Empresas pela Universidade Nove de Julho (UNINOVE).

E-mail: taisa.s@hotmail.com

\section{Priscila Rezende da Costa}

https://orcid.org/0000-0002-7012-0679

Ph.D. em Administração de Empresas; Professor Titular do Programa de Pós-Graduação em Administração de Empresas da Universidade Nove de Julho (UNINOVE). E-mail: priscilarezende@yahoo.com.br

\section{Tatiane Baseggio Crespi}

https://orcid.org/0000-0001-9740-8069

Mestre em Administração de Empresas pela Universidade Nove de Julho (UNINOVE).

E-mail: tatianebaseggiocrespi@gmail.com

\section{Claudia Brito Silva Cirani}

https://orcid.org/0000-0002-7245-3178

Ph.D. em Economia; Professor Titular do Programa de Pós-Graduação em Administração de Empresas da Universidade Nove de Julho (UNINOVE). E-mail: claudiabscirani@gmail.com 